\title{
THESIS
}

\section{EXAMINING THE ASSOCIATION BETWEEN EMOTIONAL AVAILABILITY AND MINDFUL PARENTING}

\author{
Submitted by \\ Julie Benton \\ Department of Human Development and Family Studies
}

\author{
In partial fulfillment of the requirements \\ For the Degree of Master of Science \\ Colorado State University \\ Fort Collins, Colorado
}

Spring 2017

Master's Committee:

Advisor: Doug Coatsworth Co-

Advisor: Zeynep Biringen

Lorann Stallones 
Copyright by Julie Benton 2017

All Rights Reserved 


\section{ABSTRACT \\ EXAMINING THE ASSOCIATION BETWEEN EMOTIONAL AVAILABILITY AND MINDFUL PARENTING}

This study examined the relationship between Emotional Availability (EA) and Mindful Parenting (MP), as well as their independent and combined associations with indicators of adolescent well-being. EA is a well-established measure of parent-child relationship quality, but the existing literature for EA is limited to infancy and childhood, with minimal emphasis on adolescence. There is, however, expansive support for the importance of the parent-child relationship in adolescence for well-being in adolescence and early adulthood. Mindful Parenting is one construct shown to be associated with both positive parent-child relationships and adolescent well-being. The current study tests the association among EA, MP and indicators of adolescent well-being in a sample of 30 adolescent-mother dyads participating in a longitudinal study of the Mindfulness Enhanced Strengthening Families Program (MSFP) 10-14. EA and MP were assessed through observational coding of parent-adolescent interactions. Results indicated significant associations between EA and MP, and between each construct and adolescent outcomes. Additionally, individual EA Scales and MP dimensions were established as unique predictors of adolescent outcomes. These results indicate there is a significant relationship between EA and MP and both constructs are related to adolescent outcomes, with some specific contributions to indicators of adolescent well-being. 


\section{TABLE OF CONTENTS}

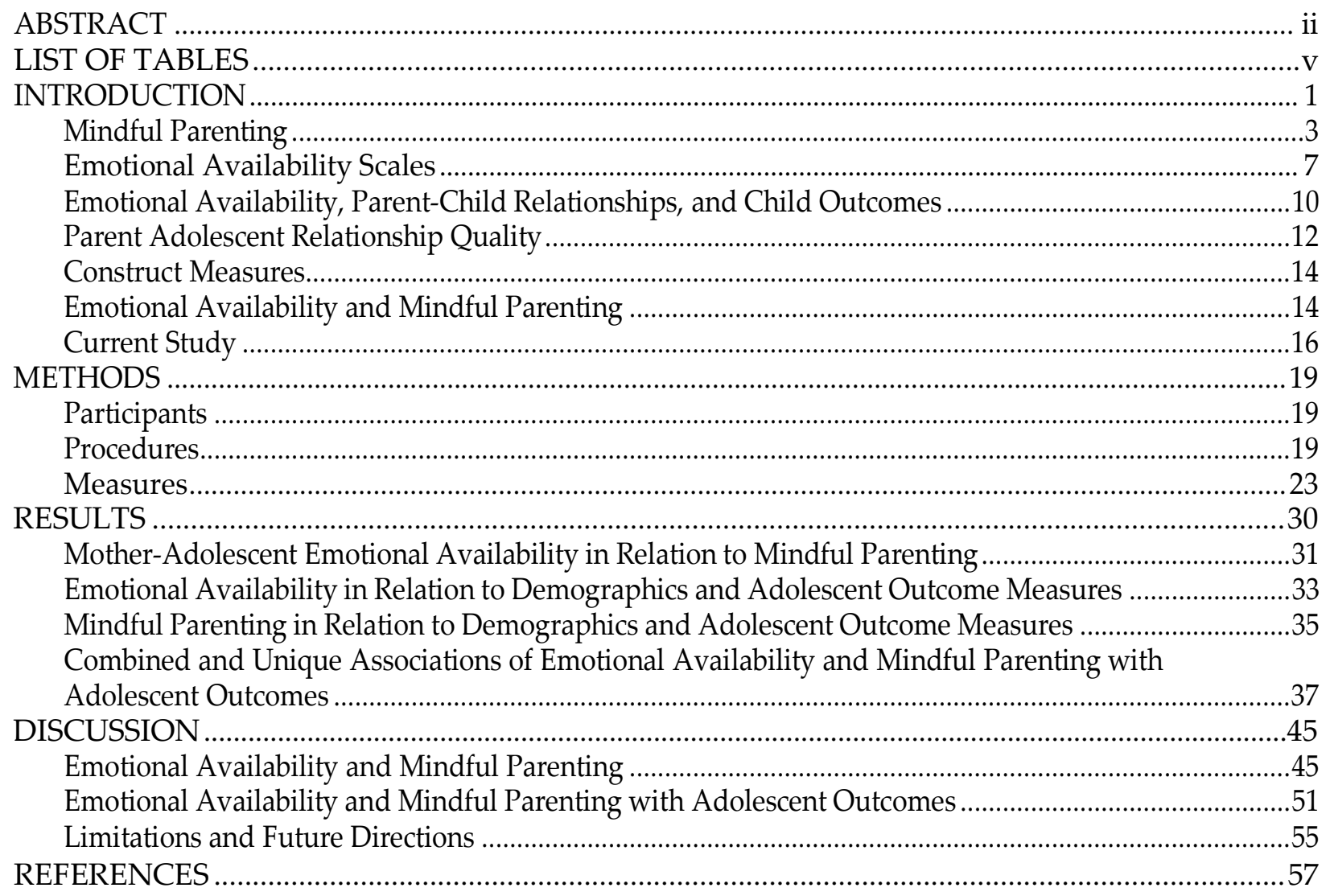




\section{LIST OF TABLES}

TABLE 1: CORRELATIONS, MEANS, AND STANDARD DEVIATIONS FOR EMOTIONAL AVAILABILITY AND MINDFUL PARENTING

TABLE 2: CORRELATIONS, MEANS, AND STANDARD DEVIATIONS FOR EMOTIONAL AVAILABILITY, ADOLESCENT OUTCOMES, AND CONTROL VARIABLES . .33

TABLE 3: CORRELATIONS, MEANS, AND STANDARD DEVIATIONS FOR MINDFUL PARENTING, ADOLESCENT OUTCOMES, AND CONTROL VARIABLES.

TABLE 4: HIERARCHIAL REGRESSION ANALYSES OF OBSERVED EMOTIONAL AVAILABILITY AND MINDFUL PARENTING PREDICTING PARENT AND YOUTH REPORTS OF YOUTH INTERNALIZING PROBLEMS .38

TABLE 5: HIERARCHIAL REGRESSION ANALYSES OF OBSERVED EMOTIONAL AVAILABILITY AND MINDFUL PARENTING PREDICTING PARENT AND YOUTH REPORTS OF YOUTH EXTERNALIZING PROBLEMS.

TABLE 6: HIERARCHIAL REGRESSION ANALYSES OF OBSERVED EMOTIONAL AVAILABILITY AND MINDFUL PARENTING PREDICTING YOUTH REPORTS OF YOUTH LIFE SATISFACTION AND AGENCY. 


\section{INTRODUCTION}

Mindfulness has become a common element of therapeutic interventions, and an approach for improving interpersonal relationships (Cohen \& Semple, 2010). The concept of Mindful Parenting (MP), and related activities to promote it within interventions, has emerged as a construct for understanding and a method for improving parent-child relationships (Duncan, Coatsworth, \& Greenberg, 2009). Research has shown that MP is associated with multiple positive aspects of the quality of parent adolescent relationships (Coatsworth, Duncan, Greenberg, \& Nix, 2010; Duncan et al., 2009; Lippold, Duncan, Coatsworth, Nix, \& Greenberg, 2015). Emotional Availability (EA) is a well-established construct of parent-child relationship quality, based in attachment and systems theories, which has shown significant associations with various positive developmental outcomes in infancy and early childhood (Biringen, Derscheid, Vliegen, Closson, \& Easterbrooks, 2014). Despite the potential applicability of EA to parentchild dyads of middle childhood and youth up to 14 years of age, and its ability to be measured in a variety of contexts, most of the EA literature has focused on infants and young children (Biringen et al., 2014). Moreover, although the definitions of the constructs of EA and mindfulness show some overlap and the descriptions of these constructs share some common features, to our knowledge these constructs have not been investigated together in a single study.

The quality of parent-child relationships in adolescence has been recognized as an important protective factor for adolescent development (Johnson \& Galambos, 2014). This suggests it may be useful to explore EA among parent-adolescent relationships. As MP continues to grow as a method of enhancing relationships, it may be especially important to investigate how it may be related to EA in parent-adolescent dyads. This study will examine the 
association between MP and EA among parent-adolescent dyads. This study will also examine the combined and individual effects of these constructs on indicators of adolescent development, including parent report of youth internalizing and externalizing behaviors and adolescentreported life satisfaction and well-being. This examination will inform further understanding of how each construct may be related to adolescent outcomes, uniquely and in combination.

Mindfulness is defined as a receptive attention to and awareness of present events and experience (Brown, Ryan, \& Creswell, 2007). This state of mind provides an alternative to automatic responses and behaviors (Duncan et al., 2009). Mindfulness has often been measured through self-report scales and defined by five mindfulness skills including "acting with awareness", "observing", "describing", "nonreactivity to inner experience", and "nonjudging of inner experience" (Baer, Smith, Hopkins, Krietemeyer, \& Toney, 2006; Carmody \& Baer, 2008). Dispositional mindfulness, or having a tendency to be mindful, represents the ability to apply the five mindfulness skills in everyday life as opposed to in a singular moment (Duncan et al., 2009). Having dispositional mindfulness has been associated with multiple outcomes such as positive affect, less depression and anxiety, and greater relationship satisfaction and less relationship stress (Baer at al., 2006; Barnes, Brown, Krusemark, Campbell, \& Rogge, 2007; Brown \& Ryan, 2003; Duncan et al., 2009).

Several studies have shown that mindfulness may be useful for interpersonal relationships and one study used a Mindfulness-Based Relationship Enhancement (MBRE) intervention, which indicated that the intervention improves psychological functioning, increases stress coping efficacy, and increases positive relationship characteristics among couples (Carson, Gil, \& Baucom, 2004). The MP model applies dispositional mindfulness concepts to the parenting context and suggests that parents who use daily mindfulness practices, to maintain 
awareness and acceptance of their child's needs, establish more satisfying parent-child relationships (Duncan et al., 2009).

One way of measuring the quality of parent-child relationships which has not been used in studies of MP, is through observational coding using the EA Scales (Biringen et al., 2014). Components of EA and MP have similarities in shared goals of improving the quality of parentchild relationships as well as some overlapping qualities in caregiving measures, suggesting a possible association. When considering MP as a contributor to relational outcomes, it may be useful to examine parent-child dyads for components of EA and determine whether there are positive associations between MP and EA. Determining an association between EA and MP would provide further support for the theory that mindful practices in the parenting context result in higher quality interpersonal relationships between parents and their children. Additionally, examining the association between EA and MP may elucidate which components of MP are most related to the quality of parent-child relationships, and how they may be uniquely related to individual outcomes.

Mindful Parenting

Duncan and colleagues proposed a conceptual model of MP that includes five dimensions: listening with full attention, nonjudgmental acceptance of self and child, emotional awareness of self and child, self-regulation in the parenting relationship, and compassion for self and child (Duncan et al., 2009). The first dimension, listening with full attention, includes correctly discerning a child's behavioral cues, and accurately perceiving the child's verbal communication. The second dimension, non-judgmental acceptance of self and child, entails a healthy balance between child-oriented, parent-oriented, and relationship-oriented goals, a sense of self-efficacy in parenting, and appreciation for the child's traits. The third dimension, 
emotional awareness of self and child, involves responsiveness to the child's needs and emotions, and accuracy in attributions of responsibility. The fourth dimension, self-regulation in the parenting relationship, refers to regulating emotions in the parenting context, and parenting in accordance with values and goals. Lastly, the fifth dimension, compassion for self and child, entails positive affection in the parent-child relationship, and a more self-forgiving view of parental efforts (Duncan et al., 2009).

Various prosocial parenting practices are designed to be promoted by each of the five dimensions of MP (Duncan et al., 2009). Listening with full attention promotes a decreased use and influence of cognitive constructions and expectations. Nonjudgmental acceptance of self and child elicits fewer self-directed concerns and unrealistic expectations of the child's attributes. Emotional awareness of self and child encourages less dismissing of the child's emotions and less discipline resulting from parent's strong negative emotions. Self-regulation in the parenting relationship promotes less over-reactive or automatic discipline and less dependence on the child's emotions. Compassion for self and child supports less negative affect displayed in the parent-child relationship and less self-blame when parenting goals are not achieved (Duncan et al., 2009).

There has been a recent focus on teaching interpersonal mindfulness to parents to improve parenting skills and to reduce risk for youth problems (Coatsworth et al., 2015). One of the important research directions to better understanding mindfulness in parenting is investigating how it influences parenting interactions and parent-child relationships. Research has shown support for associations between MP and positive outcomes for children and adolescents, as well as improvements in the quality of parent-child relationships (Duncan et al., 2009). It has been found that mindful parents have a greater ability to regulate their own 
emotions and provide consistent parenting (Parent et al., 2015). These findings are consistent across developmental stages, suggesting that positive parenting practices can have a significant impact at all ages of child development. Relational outcomes of MP include lower levels of coercive and ineffective discipline, higher levels of warmth and reinforcement, and increased parent-child communication (Lippold et al., 2015; Parent, McKee, Rough, \& Forehand, 2015).

Forehand, Jones, and Parent (2013) examined the parental role in behavioral interventions for children with anxiety and disruptive behaviors. There has been some evidence to suggest that parent and child interventions are more successful at treating anxiety problems than child-only interventions, particularly with long term outcomes. Additionally, among several interventions that include parent and child components, changes in parenting behaviors are associated with positive changes in child outcomes, with parenting as a mediator of disruptive problems (Forehand et al., 2013). These results support the importance of the parenting role in interventions for children and adolescents with internalizing and externalizing problems and of specifically targeting parenting in such interventions (Forehand et al., 2013).

Previous studies have shown that parent training programs are effective in improving parent-child relationships when they incorporate components of increasing positive interactions and improving communication (McClain et al., 2010). One study focused on parent-child relationships with children of divorced families, which has been previously identified as a risk factor for negative adolescent adaptation such as internalizing and externalizing problems. This study included youth ages 9-12 and examined cascading pathways by which the New Beginnings Program decreased symptoms of internalizing and externalizing problems through improvements in parenting. Additionally, this study investigated long-term outcomes for older adolescents (ages 15-19), through a longitudinal design, with other at-risk groups. These studies revealed 
support for a cascading model of intervention effects in that parent-child relationship quality and parenting components, such as effective discipline, predict improvements in externalizing and internalizing problems in middle childhood (McClain et al., 2010). Furthermore, cascading effects are seen to last into adolescence, affecting levels of internalizing and externalizing problems based on changes in parenting during middle childhood. These findings support reason to invest further in developing programs that teach parenting skills that will benefit the parentchild relationship. This study seeks to increase understanding of parent-adolescent relationships and define parenting elements that promote positive outcomes for adolescent well-being. Interventions designed to influence parenting have begun to incorporate activities to promote mindfulness in parenting. One intervention taught mindfulness skills to adolescents with various externalizing disorders and MP skills to their parents (Bogels, Hoogstad, Van Dun, De Schutter, \& Restifo, 2008). Results showed significant self-reported improvements in youth's personal goals, internalizing and externalizing complaints, attention problems, happiness, and mindful awareness, and performance on a sustained attention test. In addition to reports of improvement on their own goals, parents also reported improvement on children's goals, externalizing and attention problems, self-control, attunement to others, and withdrawal (Bogels et al., 2008). Interventions that have been successful at improving parent-child interactions and relationship quality suggest that further integration of MP with interventions may be useful in producing positive outcomes for adolescents and parent-child dyads. It is appropriate to consider whether the changes in parenting, specifically, are related to such outcomes.

Research has supported that MP components can enhance the effectiveness of existing parenting programs that are focused on improving parent-child relationships (Coatsworth et al., 
2015). Coatsworth et al. (2015) modified the Strengthening Families Program for Parents and Youth 10-14 (SFP 10-14), which was aimed at strengthening parent-adolescent relationships, and integrated mindfulness strategies to create the MSFP 10-14, and then compared these two interventions to determine whether MP would increase the effectiveness of the intervention. Results of the Mindfulness Enhanced Strengthening Families Program (MSFP) 10-14 intervention trial indicated the intervention is successful at improving self-reported parent child relationship quality, interpersonal mindfulness in parenting, youth behavior management, and parent well-being (Coatsworth et al., 2015). Among parent-adolescent dyads of youth aged 1014, results identified MP as a mediating factor between the intervention and improvement of parent-child relationship quality (Coatsworth et al, 2010). When mindfulness was infused in the intervention, some positive outcomes were greater than those of the standard intervention (Coatsworth et al., 2015). The MSFP 10-14 also shows an association between MP and increased parent-child communication as well as improved parental anger management and emotional reactivity among parent-adolescent dyads, controlling for age, gender, parental education, family income, and parental marital status (Lippold et al., 2015). Examining the associations between MP and EA, could provide information as to how mindfulness in the parenting context may relate to parent-child relationship quality.

\section{Emotional Availability Scales}

EA is a construct founded in attachment theory that has been proposed to reflect the dyadic quality of relationships, including relational characteristics in dyadic, emotional, and structural domains (Saunders, Kraus, Barone, \& Biringen, 2015). EA expands upon attachment theory, accounting for perspectives of the adult and child, and focusing on the emotional connection that two people share, rather than survival-based attachment behaviors alone 
(Saunders et al., 2015). Additionally, with inclusion of emotional perspectives, EA gains a more comprehensive view of the parent-child dyadic relationship, and is currently the only global system that provides such a perspective (Biringen et al., 2014). This perspective is consistent with systemic theory and differs from attachment theory as it focuses on positive as well as negative aspects of relationships, and has the capacity to be applied to multiple contexts (Biringen \& Easterbrooks, 2012).

The EA Scales were created to observationally measure EA and are comprised of four components for adults that include sensitivity, structuring, non-hostility, and non-intrusiveness, as well as two components for children including responsiveness and involvement (Biringen et al., 2014). Adult sensitivity entails a caregiver's ability to create a positive and genuine environment, as well as having a clear discernment of and appropriate responsiveness to their child's emotional expressions. It also includes elements of parental acceptance of the child. Adult structuring refers to the amount of guidance, scaffolding, and mentoring a caregiver provides to their child. This component also incorporates appropriate boundary setting and getting successful responses to demands while facilitating autonomy and internal rules for the child. Adult non-hostility involves a lack of hostility in a caregiver's interactions with their child, including covert and explicit or open forms of hostility. This might include feelings of frustration, anger, or impatience. Adult non-intrusiveness refers to the caregiver's ability to avoid over-direction, over-stimulation, interference, or over-protection. Child responsiveness encompasses positive affect and emotion regulation as well as emotional responsiveness to the adult. Child involvement includes the child's level of simple and elaborative initiative to engage the adult in an interaction in addition to the balance of autonomy and exploration (Biringen et al., 2014). 
The EA Scales have shown to be associated with attachment measures, demonstrating good concurrent validity (Easterbrooks \& Biringen, 2009). Specifically, the EA Scales have also been found to have good construct validity as attachment classifications (as measured by the Strange Situation) are significantly related to coded observations of maternal sensitivity, structuring, nonhostility, and both child responsiveness and involvement (Easterbrooks \& Biringen, 2009; Ziv, Aviezer, Gini, Sagi, \& Koren-Karie, 2000). In addition to construct validity, Altenhofen, Clyman, Little, Baker, and Biringen (2013) found convergent validity for the EA Scales, with a significant correlation between attachment security (as measured by the Attachment Q-Sort) and child involvement, child responsiveness, and maternal sensitivity. The EA Scales have also been validated cross contextually and cross-culturally (Biringen et al., 2014; Ziv et al., 2000).

The EA Scales have been found to have cross-contextual reliability when comparing scores between laboratory and home contexts with all scales showing correlation between contexts. (Bornstein et al., 2006). These findings were found using the $3^{\text {rd }}$ edition of the EA Scales for infancy; however, the EA Scales have also been validated through middle childhood with significant correlations between infant attachment and emotional availability at age 7 (Easterbrooks \& Biringen, 2009). Acceptable inter-rater reliability for the middle childhood EA Scales, specifically, has been also been found (Easterbrooks et al., 2012). An important property of the EA Scales is its sensitivity to change, which indicates that the instrument can detect changes that have occurred in relation to the therapeutic efforts of an intervention (Biringen et al., 2014). By assessing and measuring these components in relationships, EA research has informed prevention and intervention efforts to optimize conditions that promote positive 
outcomes for children and reduce negative outcomes, by helping parents establish healthy relationships and secure attachments with their children (Saunders et al., 2015).

Emotional Availability, Parent-Child Relationship Quality, and Child Outcomes

Application of the EA Scales in early childhood can be useful in providing information related to attachment security and parent-child relationship quality, as well as how these factors are associated with developmental outcomes. EA is founded on principles of attachment theory, which encompasses maternal sensitivity or a caregiver's response to a child's distress, and expands to include additional components of parent-child relationships and interactions (Easterbrooks \& Biringen, 2000). Early experiences of high emotional availability have been associated with multiple positive outcomes throughout infancy and childhood development. Specifically, higher levels of maternal sensitivity and child involvement and responsiveness are related to more secure attachment (Ziv et al., 2000). Furthermore, when considering emotional availability differences between maternal and non-maternal caregivers, caregiver sensitivity impacts infant responsiveness and involvement across caregiver relationships (Zimmerman \& McDonald, 1995). Interestingly, discrepancies in relationships between caregivers are dependent on bidirectional interactions between infants and caregivers, suggesting that the quality of the relationship and the development of EA components (such as responsiveness and involvement) differ based on each unique interaction with a caregiver (Zimmerman \& McDonald, 1995).

Some studies have used still face interactions to show poor parent-child relationship quality, or low levels of EA, is connected with disrupted emotion regulation (Kogan \& Carter, 1996). The EA Scales were used to measure the quality and components of interactions before and after the still face period. It was found that lower EA prior to the still face relates to more avoidant and resistant infant behaviors following the still face period, whereas higher EA relates 
to more responsive and involved infant reengagement behavior and less resistance and avoidance (Kogan \& Carter, 1996). The established connection between EA and emotion regulation suggests that parent-child relationship quality may contribute to the development of emotion regulation skills in stages as early as infancy.

EA has also been linked with additional outcomes such as social and language development for toddlers (Biringen et al., 2014). When comparing EA at age 3 to social components in pre-kindergarten such as complex peer play, pretend play, and exclusion by peers, results indicated that maternal structuring is associated with complex peer play as well as overall social competence (Howes \& Hong, 2008). Additionally, child involvement at age 3 is related to more pretend play and less peer exclusion in pre-kindergarten (Howes \& Hong, 2008). These findings indicate a relationship between EA and prosocial outcomes during early childhood.

Examining the quality of parent-child relationships can promote greater understanding of child outcomes as they progress through later stages of life. Most of the existing literature for EA is focused on early childhood and parent relationships with infants or pre-school aged children. Studies have shown infant attachment security is a predictor of EA in mother child relationships in middle childhood, specifically with maternal sensitivity and structuring, and child responsiveness and involvement during middle childhood (Easterbrooks, Biesecker, \& Lyons-Ruth, 2000). Easterbrooks, Bureau, and Lyons-Ruth (2012) discovered an association between aspects of emotional availability (maternal sensitivity, nonhostility, and nonintrusiveness) and functioning in older children (age 7). Child functioning was measured by controlling and disorganized attachment behavior, behavior problems in school, and self-reported depressive symptoms (Easterbrooks et al., 2012). Utilizing the EA Scales during adolescence could be valuable because parent-adolescent relationship quality is an important factor 
contributing to overall adolescent well-being, despite children becoming more independent and seeming emotionally unavailable (Biringen et al., 2014; Johnson \& Galambos, 2014). Only one known study, however, has used measures of EA with adolescents (Biringen et al., 2014; Easterbrooks et al., 2000). Enhancing parent-adolescent relationship quality has been a topic of interest for researchers in evaluating how this relationship impacts long-term outcomes for adolescents and emerging adults.

\section{Parent-Adolescent Relationship Quality}

Although research with EA in adolescence is limited, adolescence has been identified as a critical developmental stage of interest as children become more independent and develop psychosocial competencies that become a foundation for a successful transition to adulthood and later functioning (Johnson \& Galambos, 2014). Thus, relationships that are fostered during adolescence impact the way individuals interact and connect with others in adulthood. For example, a high-quality parent-child relationship is a significant protective factor in adolescent development with positive outcomes such as higher young adult intimate relationship quality and fewer internalizing and externalizing problems, including depression and low self-esteem (Johnson \& Galambos, 2014).

The quality of parent child relationships has been associated with multiple positive outcomes in adolescence. A study involving a community sample of adolescents measured attachment security in relation to major psychosocial functioning domains such as father-child relationships, peer relationships, and development of depressive symptoms and delinquent behavior across multiple time points (Allen, Porter, McFarland, McElhaney, \& Marsh, 2007). Through adolescent reports and observations of interactions, attachment security is significantly associated with internalizing and externalizing problems in adolescents. Specifically, secure 
attachment is linked to success in establishing autonomy while maintaining connection with fathers and peers, and insecure attachment is associated with increased patterns of externalizing behavior and depressive symptoms (Allen et al., 2007). In addition, McWey, Claridge, Wojciak, and Lettenberger-Klein (2015) studied self-reported parent-child relationship quality for at-risk youth whose mothers presented with depressive symptoms, which has previously been identified as a risk factor for higher internalizing and externalizing problems of adolescents. Results indicated that high mother-adolescent relationship quality is a positive intervening factor in the association between maternal depressive symptoms and adolescent internalizing and externalizing problems (McWey et al., 2015).

Continuing through the lifespan, parent-adolescent relationship quality is linked with young adult intimate relationship quality, directly and indirectly (Johnson \& Galambos, 2014). This study examined an association between parent-adolescent relationship quality and young adult intimate relationship quality, controlling for relationship quality of young adults and parents, sex, age, race, education, religiousness, relationship length, and type of intimate relationship of the young adult. Longitudinal measures were taken at four waves beginning with adolescents ranging from $7^{\text {th }}$ through 12 th grade. Results showed higher quality parentadolescent relationships are predictive of higher self-esteem, lower depressive symptoms, and higher young adult intimate relationship quality (Johnson \& Galambos, 2014). Studies such as these indicate the importance of the parent-child relationship in adolescence as it relates to longterm outcomes. They also support the need for an expanded view of contributing factors to the quality of parent-adolescent relationships. How EA in parent-adolescent relationships (as an expansion of attachment) is associated with adolescent developmental outcomes and overall well-being has not been studied yet, but the current study aims to fill this gap. 


\section{Construct Measures}

Coatsworth et al. (2010) measured parent-child relationship quality through self-report instruments targeting affective positive behavior of parents and children. Other studies have measured parent-child relationship quality similarly with items of self-report measures for parents and children; however, there has been some evidence to suggest that there are discrepancies between child and parent perceptions of parenting quality (Reidler \& Swenson, 2012). EA has been established as a valid and reliable way of measuring the quality of relationships in terms of communication and emotional connection from both parent/caregiver and child contributions, through observations of parent-child dyads (Biringen et al., 2014).

MP has predominantly been measured by self-report scales such as the Interpersonal Mindfulness in Parenting Scale, used in studies implementing the MSFP 10-14, designed with items measuring the five MP components (Coatsworth et al., 2010; Duncan, 2007). Recently, MP has been measured through observation of parent-adolescent dyadic interactions and shown preliminary evidence for a link between self-reported and observational measures of MP (Duncan, Coatsworth, Gayles, Geier, \& Greenberg, (2015). For the current study, observational coding of mother-adolescent interactions will be used to examine the association between observed MP and observed EA.

\section{Emotional Availability and Mindful Parenting}

There are multiple conceptual similarities between EA and MP as well as shared relational goals for parent-child interactions. As parents are able to recognize emotions in themselves and in their child through mindful awareness in interactions, they will be less likely to respond automatically and can make conscious decisions about how they will react in a particular situation (Duncan et al., 2009). This view of MP may have interesting implications for 
parent-child relationship quality as parents may increase their capacity to be emotionally available to their children (Biringen et al., 2014). Support for this connection is offered by Harnett and Dawe (2012) with a theoretical integrated model of family functioning, proposing that MP contributes to self-regulatory capacities in parents, which allows them to be more emotionally available in interactions with their children. Multiple connections between specific elements of each construct are considered within the current study. For example, outcomes of MP, such as increased communication, may relate to EA components of child involvement and responsiveness. Additionally, components of mindfulness in parenting such as listening with full attention, nonjudgmental acceptance of self and child, emotional awareness of self and child, and self-regulation all share common themes with the EA dimensions of caregiver sensitivity and non-hostility. Through applying mindfulness in parenting, caregivers may find it easier to monitor their own behavior in response to the needs or expressions of their child, which is consistent with adult EA components.

More specifically, the EA dimension of adult sensitivity and the MP component of listening with full attention both involve a caregiver's capacity to accurately discern their child's expressions, with one being specific to emotions and the other to behavioral or verbal expressions (Biringen et al., 2014; Duncan et al., 2009). Additionally, the MP component of self-regulation in the parenting relationship is consistent with the EA subscale of adult nonhostility as it is ideal to reduce or eliminate negative affective expressions such as frustration, anger, or impatience. Finally, there is overlap between EA components of adult sensitivity as it requires parental acceptance of their child, which is shared with the MP non-judgmental acceptance element that requires appreciation for the child's traits (Biringen et al., 2014; Duncan et al., 2009). Conceptual overlaps between EA and MP are depicted in figure 1. 


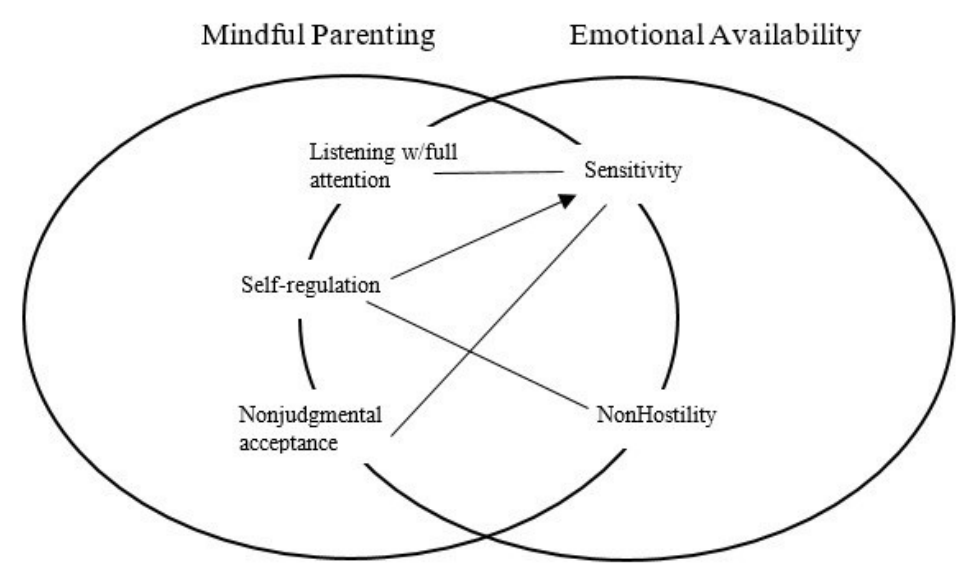

Figure 1. Conceptual overlaps between EA and MP dimensions.

EA differs from MP in its focus on nonverbal communication in a parent-child interaction, as well as its consideration of child perspectives and responses as part of the evaluation of a parent. EA also emphasizes attachment-relevant functioning in its components as opposed to mindfulness practices alone. Conceptually, mindfulness in parenting may contribute to more secure attachment functioning, but does not directly address attachment. Finally, some contexts may indicate greater discrepancies between the two constructs, such as when parental behaviors contribute to a more emotionally available interaction based on the child's response, but may not rate highly in terms of mindfulness in parenting.

\section{Current Study}

This study will examine the potential association between EA and MP in motheradolescent relationships. Specifically, mother-child interactions will be assessed for EA and MP and the associations between these two constructs will be assessed. The purpose of this study will be to examine the associations between aspects of MP and aspects of EA and to test their combined and unique associations with youth outcomes. These examinations will increase understanding of mother-adolescent relationships and components that contribute to the quality 
of these relationships. This understanding will benefit future studies that aim to improve motherchild relationships and the development of interventions to support this goal.

Enhancing mother-adolescent relationships is an important method for preventing maladaptive outcomes and promoting overall social and emotional well-being in adolescence. MP has been identified as an effective parenting tool in promoting positive child development and improving mother-adolescent relationships. Because EA is a well-documented measure of mother-child relationship quality that shares some underlying theoretical connections to mindfulness, and because EA is also applicable to older youth, it is reasonable to consider how these two constructs may be associated empirically. This study will be the first one to empirically examine these associations and to investigate the unique and combined effects that EA and mindful parenting have on youth outcomes. Two main research questions guide the current study. The first question is what is the association between mindfulness in parenting and Emotional Availability. Because this is the first study to investigate these associations, no empirical studies were available to guide hypotheses. However, as described above, these two constructs are conceptually similar, so I anticipate the global scores on these scales will demonstrate modest to strong positive associations, after controlling for background demographic characteristics. The second question examines the unique and combined associations that EA and MP have with indicators of adolescent behavior problems (internalizing and externalizing) and well-being (life satisfaction and agency). Although these two constructs are conceptually similar, I hypothesize that EA and MP will demonstrate unique positive associations with well-being and negative associations with youth behavior problems. The suggested correlation between EA and MP and their relations to adolescent outcomes is depicted in figure 2. 


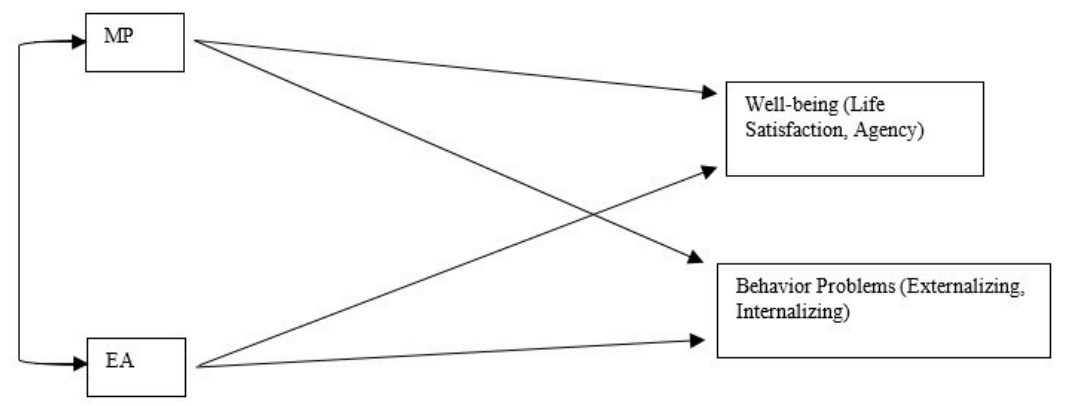

Figure 2. Suggested unique and combined relationships between EA and MP with adolescent outcomes. 


\section{METHODS}

\section{Participants}

The sample for this study was comprised of 30 mother-adolescent dyads. The sample was evenly split by gender (47\% Males), with average youth age of $12.4(\mathrm{SD}=.66)$. Families had an average income of $\$ 63,536(\mathrm{SD}=\$ 45,936)$, with $50 \%$ of mothers having graduated from college. Racial diversity was consistent with the demographics of the region, with $80 \%$ of mothers selfreporting as White and 20\% as non-White (Black/African American or Hispanic). Two-thirds of the families were from two-parent homes with mothers reporting being married or in a stable, marriage-like relationship.

\section{Procedures}

The current study is a secondary analysis of a larger randomized trial of the Mindfulness Enhanced Strengthening Families Program (MSFP 10-14) intervention (Coatsworth et al., 2015). The original project included families of $5^{\text {th }}, 6^{\text {th }}$, and $7^{\text {th }}$ grade students who were recruited from three rural school districts in central Pennsylvania (Coatsworth et al., 2015). Assessments were completed just before and after the intervention and surveys were mailed at both times to participating families. Following baseline assessments, families were randomly assigned to three conditions including the original SFP 10-14 program the MSFP 10-14, and delayed home study intervention control condition. Data for the current study are taken from post-intervention assessments. To control for possible intervention effects, analyses will include the intervention condition (SFP, MSFP or control) as a control variable.

Intervention Procedures

SFP 10-14 is an evidence-based, universal, family-focused intervention designed to prevent the onset and escalation of adolescent substance use and problem behavior. The 
intervention consists of seven two-hour sessions, delivered to groups of mothers and youth. Sessions are typically delivered one session per week and are structured such that mothers and youth meet in separate groups for the first hour and conjointly in a family session during the second hour. See Molgaard, Spoth, and Redmond (2000) for a full description of the intervention. The mindfulness-enhanced strengthening families program (MSFP) was designed with an identical format of the original SFP 10-14 in aspects such as session number, length, and timing (Coatsworth et al., 2015), but mindfulness activities were infused to the parent training portion of the curriculum. Youth and family components of the curriculum remained identical to the original SFP 10-14. Researchers collaborated with the lead author of the original SFP to infuse parent sessions only with new mindfulness activities. This process also included modifying length, order, and phrasing of some original activities in order to emphasize messages of mindful parenting such as being attentive, reducing emotional reactivity, and being less judgmental. A more complete description of the parent study and MSFP intervention is available elsewhere (Coatsworth et al., 2015).

Video Interaction Task

As part of the assessment procedures for the original project, mothers and adolescents participated in a video recorded 15-minute structured interaction task. For past evaluations of SFP 10-14, the task has been used to generate data as rated by the Iowa Family Interaction Rating Scales, $5^{\text {th }}$ Edition (IFIRS; Melby et al., 1989). In the interaction task, the mother and youth discussed a series of 13 questions about the nature of their relationship. Questions were designed to elicit increasingly strong emotional responses and potential for disagreement. Example questions included "How do I know what's going on in my child's life, like in school, 
friends or other activities”; and “What does mom say when I do something she doesn't like? Does she always do what she says she will do when this happens?”

For the current study, 30 video recordings of mother-adolescent dyadic interactions from postintervention observations were selected. All cases with codeable videos $(\mathrm{N}=275)$ were stratified by the three intervention conditions (SFP MSFP 10-14 and control) and ten from each were randomly selected for this study. Videos were coded using an adapted version of the Mindful Parenting Observational Scales (MPOS; Geier, Coatsworth, Turskma, \& Greenberg, 2012) and the EA Scales coding manual, $4^{\text {th }}$ edition (Biringen, 2008).

Coding Procedures

Coding using the adapted version of the MPOS was conducted by one of the developers of the scales who is also a gold standard coder. EA in mother-adolescent relationships was double coded for all 30 videos by the first author and a gold standard coder, using the EA Scales.

Coder Training for Emotional Availability Scales: It is required to complete training before gaining access to the EA Scales coding manual and approval for using them, and can be requested from the author (Biringen, 2005). Training includes reliability coding with a series of videos that have been validated against the Strange Situation and Adult Attachment Interview, in an effort to achieve uniform scoring across coders and inter-laboratory reliability. Adequate reliability is considered to be within 1 point of Gold Standard scores, using standardized training videos. Upon completing inter-laboratory reliability training, coding of additional videos is suggested to achieve within-study reliability (Biringen, 2005). For the current study, two researchers who had completed such training coded the videos using the EA Scales and interrater reliabilities were calculated. Two initial videos of the sample from the present study were used to establish within-study reliability, prior to continuing with the remainder of the sample. 
After achieving reliability between coders, the remaining videos were coded in groups of ten. Upon completion of initial coding, each coder individually sent scores to an unbiased source to maintain confidentiality. ICC scores for each scale was calculated. If the ICC for a scale did not meet the minimum criteria of .70 , then coders would discuss the scale conceptually, but not the specifics of any given case, and recode that scale for each of the 10 cases. After recoding, ICC was recalculated in all cases, following this procedure until it yielded an adequate ICC for the scale in question. After adequate inter-rater reliability was achieved on all scales, coders would conference scores for individual cases with discrepancies of 1.5 points or greater which resulted in a consensus score for each EA scale. Conferencing also occurred for the two Clinical Screener scores, which are the two global rating scales that categorize mothers and youth separately into zones representative of their overall emotional availability and emotional attachment, where higher scores represent more secure attachment with more emotional availability and lower scores represent insecure to disorganized attachment. Discrepancies between coders, such as the mother or youth being in a different zone of Emotional Availability (attachment) would be conferenced until there was agreement for a particular zone. If a consensus score was not achieved, coders would consult a third-party member to find agreement on a consensus score to be used. Coders would then move on to the next set of ten videos and follow this process for each set. For data analysis, scores from the primary coder were used, except when there was a discrepancy in scores that required conferencing, then that conferenced score was used instead. Across the 30 cases the ICC for the EA Scales ranged from .70-.94, indicating strong inter-rater reliability. 


\section{Measures}

\section{Emotional Availability}

Mother-adolescent interactions were coded for Emotional Availability using The Emotional Availability Scales $4^{\text {th }}$ edition for middle childhood/youth (Biringen, 2008). Quality of motherchild interactions and relationship were coded on six relationship dimensions: including adult sensitivity, adult structuring, adult non-hostility, adult nonintrusiveness, youth responsiveness, and youth involvement (Biringen, 2008). Mother-child emotional attachment was assessed using the Emotional Attachment \& Emotional Availability Clinical Screener, which is an observational scale that yields scores within four global zones ranging from 1 to 100 (EA2-CS; Biringen, 2008). Relationships were categorized within these four zones and represent attachment as emotionally available (81-100), complicated emotional availability (61-70), emotionally unavailable/ detached (41-60), and problematic/disturbed (1-40) (Biringen, 2008).

Adult Sensitivity ranges from 1 ("Insensitive") to 7 ("Highly Sensitive") and captured appropriateness of a mother's affect and behavior in the interaction (Biringen, 2008). This measure assessed the amount of warmth and enjoyment of the interaction by both the mother and child as evidenced by pleasant facial expressions and tone of voice, and comfortable physical and eye contact. This scale also assessed a mother's ability to appropriately detect and respond to their child's signals or cues such as in a situation of distress. Other components include mothers' awareness of timing, acceptance of the child, and amount of age appropriate interaction with appropriate flexibility for play themes, and ability to skillfully resolve conflicts (Biringen, 2008).

Adult Structuring ranges from 1 ("Non-optimal") to 7 ("Optimal") and captured the amount of guidance and support that a mother provided for the child while allowing for an appropriate 
amount of autonomy (Biringen, 2008). Also captured were how successful bids for structuring were and how well the mother provides a firm but not harsh level of discipline, while remaining firm under pressure from the child. Additional components include adult utilization of nonverbal and verbal forms of structuring and ability to maintain a parental role as opposed to a peer-like role as evidenced by posture, tone of voice, or facial expressions (Biringen, 2008).

Adult Nonintrusiveness ranges from 1 ("Intrusive") to 7 ("Nonintrusive) and captured how well a mother allowed their youth to lead interactions and to explore autonomy without overpowering the interaction (Biringen, 2008). Also assessed were the mother's ability to find non-interruptive points of entry to the interaction without causing a feeling of intrusiveness to the youth, as evidenced by youth's reactions and behaviors; the use of few commands; and talking as an interactional communication tool, allowing space for the youth to contribute and respond. This scale also incorporated how well the mother taught with the purpose of relating, facilitated participation while actively listening, and limited physical or verbal interferences to a minimum. (Biringen, 2008).

Adult Nonhostility ranges from 1 ("Hostile") to 7 ("Nonhostile) and encompassed lack of overt and covert forms of hostility which are evidenced by negativity in face or voice, and in words or deeds (Biringen, 2008). Additional components include a lack of the following: demeanor or statements that are mocking or disrespectful of the youth, threats of separation, frightening statements, inappropriate silence, and unresolved negative play themes. Also incorporated was the mother's ability to maintain composure during stressful circumstances and not become stressed or dysregulated (Biringen, 2008).

Youth Responsiveness ranges from 1 ("Non-optimal in Responsiveness") to 7 ("Optimal in Responsiveness") and assessed for an affectively positive stance evidenced by pleasure in the 
interaction and an appearance of genuine contentment (Biringen, 2008). Other measures include amount of well-balanced emotion regulation that is age appropriate and showed predictability and organization of affect, frequency of responsiveness to bids from the mother while balancing appropriate level of autonomy, physical positioning that welcomed interaction, lack of role reversal or avoidance of the mother, and being appropriately task-oriented or focused on an activity (Biringen, 2008).

Youth Involvement ranges from 1 ("Non-optimal Involvement) to 7 ("Optimal Involvement") and assessed for youth's attempts to eagerly engage the mother without anxiety or negativity and without compromising autonomy (Biringen, 2008). This scale also assessed for use of visual, physical, and verbal connection with the mother as well as lack of negatively involving behaviors such as irritation or anger. Other components include use of simple initiatives, such as looking or talking, and elaborate initiatives, such as creating an elaborated exchange with the mother (Biringen, 2008).

The EA Scales have been found to have inter-rater reliability in numerous examples (Biringen et al., 2014). Cross-contextual reliability as also been established with significant correlations between EA scores collected in the laboratory and home contexts (Bornstein et al., 2006). The EA Scales have also been found to have construct validity and cross-cultural applicability as Ziv et al. (2000) found that attachment classifications are significantly related to maternal sensitivity, and both child responsiveness and involvement. Lastly, Altenhofen et al. (2013) found convergent validity for the EAS with a significant correlation between child involvement and attachment security. Convergent validity was also found between child attachment and EA dimensions of maternal sensitivity and child responsiveness (Altenhofen et al., 2013). 


\section{Mindful Parenting}

Mothers' mindful parenting was assessed observationally using an adapted version of the Mindful Parenting Observational Scales (MPOS; Geier, Coatsworth, Turskma \& Greenberg, 2012). The original measure consists of 17 behavioral rating scales of parenting behavior that assess various facets of how mindful parenting is hypothesized to manifest interpersonally, and 1 rating of youth behavior. On the original scales, ratings on each scale are made on a Likert-type response scale ranging from 1 (“Low"/“None”) to 5 ("High”). These scales are combined into composite scores reflecting the five dimensions of mindfulness in parenting articulated by Duncan and colleagues (2009): Listening with full attention; emotional awareness of self and child; nonjudgmental acceptance of self and other; self-regulation in parenting relationship; compassion for self and other. For the adapted version of the scales used in this study, a global rating was made for each of the five dimensions and one overall global scale. Each dimensional rating was based on similar concepts as the sub-items of the MPOS, even though ratings were not made on those sub-items. All ratings were made on a 1-5 likert scale.

Listening with Full Attention was based on two broad concepts of Attentive Listening, which means the extent to which a mother reflects a present-centered focus on her child through her listening behavior, and Verbal Reciprocity, which means the extent to which the mother is an active and willing participant in the interaction and how well she aligns her speech with meaning conveyed by her child (Bryan et al., 2016).

Emotional Awareness of Self and Child assessed the frequency of the mother's use of emotion words to describe global or discrete emotional states (e.g. "I felt sad when you didn't make the team, too.") that reference the mother or the child (Bryan et al., 2016). 
Nonjudgmental Acceptance of Self and Child reflected mother's degree of Openness/Acceptance, meaning her interest in and openness towards her youth's opinions, attitudes, behavior, attributes, and emotions, with minimal evaluation or judgment, and Validation, the mothers' level of communication of understanding and/or agreement with a youth's statements and emotions a mother employs (Bryan et al., 2016).

Self-Regulation in the Parenting Relationship reflected mothers' Defensiveness, meaning her behavior that is characterized by attempts to avoid responsibility, blame, or judgment, Wait time, representing an aspect of reactivity referring to the time between when a youth stops talking and when the mother begins, Negative Emotional Valence, which assessed the frequency of negative affect in mothers' responses to youth and, Intensity which refers to the emotional strength, magnitude, and meaning of a mother's responses (Bryan et al., 2016).

Compassion for Self and Child reflected the extent to which mother expressed Contempt, or blatant disrespect or disregard for her child, often in a hurtful, humiliating, or belittling manner, Affection, reflecting frequency and strength of clear, intentional displays of caring, concern, comfort, and love. Compassion addressed the level of recognition, empathy, and childcenteredness in the way a mother approaches her youth when the youth displays an actual or potential experience of negative emotion (Bryan et al., 2016).

Global ratings were made based on the entire interaction. Bryan et al. (2016) discovered that the original MPOS measure can be reliably coded by independent observers and acceptably compares to other established and similarly structured observational measures.

\section{Adolescent Behavior Problems}

Mothers and fathers reported on their youths' internalizing and externalizing symptoms using the Child Behavior Checklist (Achenbach \& Rescorla, 2001). This is a frequently used measure 
with well-established reliability and validity (Achenbach \& Rescorla, 2001). In this study, the two broad-band measures of internalizing, indicating behaviors reflecting anxiety, depression and somatization, and externalizing, indicating behaviors of aggression, attention problems and minor delinquency, were used. Internal consistency reliability for internalizing $(\alpha=.91)$ and externalizing $(\alpha=.94)$ in the original study was excellent.

\section{Adolescent Well-being}

Adolescent well-being was assessed using the Student Life Satisfaction Scale (Huebner, 1991), and Youth Agency Scale (Bradley, 2013). The life satisfaction scale is the most commonly used measure of child and youth satisfaction with life. It contains seven broad items reflecting youth report of how satisfied they are with their life (e.g. "My life is just right") all reported on a 5 point Likert-type scale $(1=$ strongly disagree to $5=$ strongly agree $)$. This measure has been shown to have good construct validity through appropriate associations with other life satisfaction measures and concurrent validity through associations with related outcomes such as depression, anxiety, social stress, loneliness, and aggressive behaviors (Huebner, Suldo, \& Valois, 2003). This measure has also shown appropriate discriminant validity wherein life satisfaction measures are not correlated with IQ scores or grades, as well as predictive validity which indicates life satisfaction as a protective factor against adverse life events in adolescence (Huebner et al., 2003). The Life Satisfaction Scale also shows significant test-retest reliability across several time points (Huebner et al., 2003). In the original study, this measure showed good internal consistency reliability $(\alpha=.86)$ (Coatsworth et al., 2015). The Youth Agency Scale is a brief, 9 item measure developed for the original study (Bradley, 2013) designed to measure adolescent intrinsic motivation ( e.g., "I feel inspired to do things that interest"), behavioral agency (e.g., "I take action to do the things I want to do"), and cognitive 
agency/goal direction ("I think of different ways to reach my goals"). This measure has shown good internal consistency reliability $(\alpha=.81)$. The measure also showed good concurrent validity with otherindicators of youth functioning(Bradley, 2013). 


\section{RESULTS}

Preliminary Analyses

Preliminary analyses were conducted to examine the distributions of and intercorrelations among the study variables. Correlations among variables and each variable's mean and standard deviation are presented in tables 1,2, and 3. All study variables showed relatively normal distributions with skew/Standard Error of skew less than 1.96. In addition, one-way Analysis of Variance tests were conducted on all independent and dependent variables to determine if there were differences by intervention condition. Only youth report of internalizing met a level of p $<=.10 ; \mathrm{F}(2,27)=2.52, \mathrm{p}=.09$. Condition was therefore included as a control variable in analyses involving youth report of internalizing symptoms. Demographics and Outcome Variables

Correlations between the study's demographic variables, the EA variables, the MP variables and the adolescent outcome variables (youth life satisfaction, youth agency, and parentand youth-reported youth internalizing and externalizing problems) are presented in tables 2 and

3. Higher income is associated with higher mother education level. Youth externalizing problems, as reported by parents, are positively associated with youth age. Youth gender is also significantly and positively associated with family income and mothers' education level, such that boys came from families with higher income and higher mothers' education.

Adolescent outcome measures are also strongly and significantly intercorrelated. Life satisfaction and agency were positively correlated and both were strongly negatively correlated with internalizing and externalizing scores from parent and youth reports. As expected, youth reports of internalizing and externalizing are correlated and parent reports of internalizing and 
externalizing are correlated. Externalizing reports from parent and youth are strongly correlated, but internalizing reports across reporters are not. There are small nonsignificant associations between parent-reported youth externalizing problems and both youth-reported internalizing and externalizing problems.

Mother-Adolescent Emotional Availability in Relation to Mindful Parenting

The hypothesis that Emotional Availability (EA) would be significantly correlated with Mindful Parenting (MP) was tested using correlation analysis (see table 1). With only a few exceptions, all adult EA variables (nonintrusiveness mother clinical screener scores, adult sensitivity, adult structuring, and adult nonhostility) are significantly correlated with MP variables (global MP scores, listening with full attention, emotional awareness of self and child, parent self-regulation, nonjudgmental acceptance of self and child, and compassion for self and child). Statistically significant correlations range $.37-.59$ with only moderate nonsignificant correlations between compassion for self and child and both structuring and youth responsiveness. There is also a small nonsignificant correlation between adult nonhostility and listening with full attention. Nonintrusiveness shows only modest nonsignificant correlations with MP variables. Youth involvement and youth clinical screener scores also have modest nonsignificant correlations with MP variables, aside from self-regulation, which are statistically significant associations. Although highly influenced by youth responsiveness, youth clinical screener scores have more similar correlation patterns to youth involvement with small to moderate nonsignificant correlations with MP variables, except for moderate significant correlations with parental self-regulation. Except for nonintrusiveness, EA variables show the strongest correlations with the MP variable of parental self-regulation. 
Table 1

Correlations, means, and standard deviations for Emotional Availability and Mindful Parenting

\begin{tabular}{|c|c|c|c|c|c|c|c|c|c|c|c|c|c|c|}
\hline & 1 & 2 & 3 & 4 & 5 & 6 & 7 & 8 & 9 & 10 & 11 & 12 & 13 & 14 \\
\hline 1.EA Mother CS & 1 & & & & & & & & & & & & & \\
\hline 2. EA Sensitivity & $.92 * 4$ & 1 & & & & & & & & & & & & \\
\hline 3. EA Structuring & $.76^{4+}$ & $.79 * 4$ & 1 & & & & & & & & & & & \\
\hline 4. EA NonIntrusiveness & $.47^{* 4}$ & $.50^{* 4}$ & .27 & 1 & & & & & & & & & & \\
\hline 5. EA NonHostility & $.66^{4+}$ & $.67^{4 *}$ & $.52^{4 *}$ & $.57^{4 *}$ & 1 & & & & & & & & & \\
\hline 6. Youth Responsiveness & $.71^{4 *}$ & $.72 * 4$ & $.70^{4 *}$ & $.40^{\circ}$ & $.60^{44}$ & 1 & & & & & & & & \\
\hline 7. Youth Involvement & $.54 * 4$ & $.57^{4 *}$ & $.63^{* 4}$ & $.50^{4 *}$ & $.54^{* 4}$ & $.85^{* 0}$ & 1 & & & & & & & \\
\hline 8. EA Youth CS & $.68^{4+4}$ & $.69 * 4$ & $.67^{4 *}$ & $.49 * 4$ & $.54^{* 4}$ & $.88 * 0$ & $.83^{* 0}$ & 1 & & & & & & \\
\hline 9. MP Global & $.53^{* 4}$ & $.59 * 4$ & $.54^{4 *}$ & .22 & $.38^{*}$ & $.41^{*}$ & .33 & .33 & 1 & & & & & \\
\hline 10. MP Listen w/Full Attm. & $.44^{\circ}$ & $.48^{* 4}$ & $.41^{*}$ & .24 & .25 & $.42^{*}$ & .24 & .31 & $.80^{* *}$ & 1 & & & & \\
\hline 11. MP Emotional Aware. & $.48^{* 4}$ & $.52 * 4$ & $.46^{\circ}$ & .08 & $.41^{\circ}$ & $.37^{*}$ & .27 & .24 & $.84^{* 0}$ & $.69 * 0$ & 1 & & & \\
\hline 12. MP Self Regulation & $.56^{* 4}$ & $.59 * 4$ & $49 * 4$ & .26 & $.44^{\circ}$ & $.51^{* *}$ & $.41^{*}$ & $.42^{*}$ & $.74 * 0$ & $.71^{40}$ & $.68 * 0$ & 1 & & \\
\hline 13. MP NonJudge Accept. & $.52 * 4$ & $.58 * 4$ & $.45^{\circ}$ & .20 & $.45^{\circ}$ & $.37^{*}$ & .28 & .20 & $.85^{\circ}$ & $.64 * 0$ & $.81 *$ & $.57^{* *}$ & 1 & \\
\hline 14. MP Compassion & $.49 * 4$ & $.55^{* 4}$ & .36 & .28 & $.37^{*}$ & .35 & .29 & .24 & $.92^{* *}$ & $.68 * 0$ & $.80^{\circ *}$ & $.62^{* *}$ & $.88^{\circ *}$ & 1 \\
\hline \multirow{2}{*}{$\begin{array}{l}M \\
S D\end{array}$} & 76.47 & 4.68 & 4.37 & 4.55 & 4.92 & 4.75 & 4.95 & 77.03 & 2.78 & 2.77 & 2.47 & 2.95 & 2.80 & 2.77 \\
\hline & 12.32 & 1.06 & 1.04 & .98 & 1.34 & 1.32 & 1.37 & 12.29 & .81 & .93 & .73 & .76 & .71 & .65 \\
\hline
\end{tabular}

$*=p<.05, * *=p<.01$ 
Emotional Availability in Relation to Demographics and Adolescent Outcome Measures

Correlations were also used to test the hypothesis predicting that Emotional Availability (EA) would have significant associations with adolescent outcome measures. Demographic variables are also associated with some EA variables. Adult sensitivity and maternal emotional availability increase as income increases. Maternal emotional availability, adult sensitivity, adult structuring, and youth involvement are positively associated with mothers' level of education. Mother-Adolescent Emotional Availability in Relation to Youth Life Satisfaction

EA Scales show modest associations with life satisfaction. Specifically, maternal emotional availability, adult sensitivity, adult structuring, youth responsiveness, and youth involvement are significantly positively correlated with youth life satisfaction, ranging from .40.52

Mother-Adolescent Emotional Availability in Relation to Youth Agency

There are small non-significant positive correlations between maternal clinical screener scores, adult structuring, youth responsiveness, and youth involvement and youth agency. Additionally, there are small insignificant negative correlations between adult nonintrusiveness and adult nonhostility and youth agency.

Mother-Adolescent EA in Relation to Youth Internalizing and Externalizing Problems Correlations between EA and youth internalizing and externalizing problems are weak to moderate in size. Adult nonhostlity and youth responsiveness are significantly negatively associated with parent reported youth externalizing problems. Youth responsiveness is also significantly negatively correlated with parent reported youth internalizing problems. 
Table 2

Correlations, means, and standard deviations [gr Emotional Availabili!J::. and adolescent outcome and control variables

\begin{tabular}{|c|c|c|c|c|c|c|c|c|c|c|c|c|c|c|c|c|c|c|c|}
\hline & $\mathrm{I}$ & 2 & 3 & 4 & 5 & 6 & 7 & 8 & 9 & 10 & II & 12 & 13 & 14 & 15 & 16 & 17 & IS & 19 \\
\hline I.Sex & I & & & & & & & & & & & & & & & & & & \\
\hline 2. Jlge & .08 & I & & & & & & & & & & & & & & & & & \\
\hline 3. Income & $.39 *$ & .22 & & & & & & & & & & & & & & & & & \\
\hline 4. Race & .24 & -.04 & .07 & I & & & & & & & & & & & & & & & \\
\hline 5.Education & so•• & .14 & $.37 *$ & .28 & & & & & & & & & & & & & & & \\
\hline 6. Life Satisfaction & .14 & -.29 & .17 & -.01 & .31 & & & & & & & & & & & & & & \\
\hline 7.Youth Agency & .30 & -.33 & .16 & .08 & .15 & ?'** & & & & & & & & & & & & & \\
\hline 8.Externalizing YR & .03 & 29 & -.02 & -.36 & .07 & $-.53^{* *}$ & $-.43^{*}$ & & & & & & & & & & & & \\
\hline 9.E.xternalizing PR & .25 & $.44^{*}$ & .03 & .24 & -.07 & $-.59 * *$ & $-.48^{* *}$ & .22 & & & & & & & & & & & \\
\hline 10. Internalizing YR & -.13 & .18 & -.06 & -.23 & -.12 & $-.71^{\star *}$ & $-.51^{\star *}$ & $.71 * *$ & 20 & & & & & & & & & & \\
\hline 11.Internalizing PR & .05 & .33 & .03 & -.03 & -.00 & $-.60^{* *}$ & $-.67^{* *}$ & $.39 *$ & $.71^{* *}$ & $.55 * *$ & & & & & & & & & \\
\hline 12.EA 1.lllother CS & .12 & 04 & .38 & .19 & $.48 * *$ & $.42 *$ & .20 & -.28 & -28 & -.26 & -.30 & & & & & & & & \\
\hline 13.EA Sensitivity & .12 & .15 & .4 & .16 & $5^{11 * *}$ & $.40 *$ &. $\mathrm{OS}$ & -.17 & -29 & -23 & -.20 & $n \bullet \bullet$ & & & & & & & \\
\hline 14.EA Structuring & .22 & -.06 & .34 & .32 & $.49 * *$ & $.42 *$ & .27 & -.20 & -.26 & -.15 & -.16 & $.76^{* *}$ & $.79 * *$ & & & & & & \\
\hline 15.EA Nonlntrusiveness & -.05 & .01 & .21 & -.18 & .25 & .14 & -.11 & 07 & -28 & 03 & -.12 & $.47^{* *}$ & $.50^{* *}$ & 27 & & & & & \\
\hline 16.EA NonHostility & -.04 & -.02 & .14 & -.05 & .44 & .26 & -.02 & .05 & $-.48 * *$ & 05 & -.22 & $.66^{* *}$ & $.67 * *$ & $.52 * *$ & $.57 * *$ & & & & \\
\hline 17.Youth Responsiveness & -.05 & -.10 & .15 & .24 & .29 & $.52 * *$ & .24 & -34 & $-.48 * *$ & -32 & $-.46 *$ & $11 \cdot 0$ & $.72 * *$ & $.10 \bullet$ & $.40 *$ & $.60 * *$ & & & \\
\hline 18. Youth Involvement & .04 & -.16 & .06 & .24 & $.39 *$ & $.48^{* *}$ & .20 & -30 & -.35 & -.27 & -.22 & $.54 * *$ & $.57^{* *}$ & $65^{\prime \prime * *}$ & $.50 * *$ & $.54 * *$ &.$s S^{\bullet \bullet}$ & & \\
\hline 19.EA Youth CS & .00 & -.09 & .29 & .31 & .33 & $.41^{*}$ & .05 & -33 & -20 & -.24 & -.16 & $.68 * *$ & $69 * *$ & $.67^{* *}$ & $.49 * *$ & $.54 * *$ & $.88^{* *}$ & $8)^{\prime \prime * *}$ & \\
\hline$M$ & .47 & 1229 & 69,211 & 1.67 & 5.13 & 2.87 & 2.15 & 8.13 & 6.9 & 6.83 & 6.7 & 76.47 & 4.68 & 4.37 & 4.55 & 4.92 & 4.75 & 4.95 & 77.03 \\
\hline$S D$ & .51 & 68 & 42,474 & .48 & 1.38 & .75 & .49 & 8.19 & 6.34 & 7.57 & 7.86 & 12.32 & 1.06 & 1.04 & .98 & 1.34 & & 1.37 & 12.29 \\
\hline
\end{tabular}

$\bullet=p<.05, \bullet=p<.01$ 
Mindful Parenting in Relation to Demographics and Adolescent Outcome Measures

Correlation analyses were used to test the hypothesis predicting significant associations between Mindful Parenting (MP) variables and adolescent outcomes. There are significant correlations between maternal education and four MP variables, including global scores, listening with full attention, emotional awareness of self and child, and nonjudgmental acceptance of self and child. As presented in table 3, overall, there are weak to moderate correlations between MP variables and adolescent outcomes.

Mindful Parenting in Relation to Youth Life Satisfaction

Nonjudgmental acceptance of self and child has a significant moderate correlation with life satisfaction. There are nonsignificant correlations of moderate size between all other MP variables and life satisfaction except for a small nonsignificant correlation between listening with full attention and life satisfaction.

Mindful Parenting in Relation to Youth Agency

There are small nonsignificant correlations between emotional awareness of self and child, nonjudgmental acceptance of self and child, and compassion for self and child with youth agency.

Mindful Parenting in Relation to Youth Internalizing and Externalizing Problems

There are small to moderate nonsignificant correlations between MP variables and both parent and youth reports of youth internalizing and externalizing problems. 
Table 3

Correlations, means, and standard deviationsfor Mindfal Parenting and adolescent outcome and control variables

I. Sex

2. Jlge

3. Income

4. Race

5. Education

6. Life Satisfaction

7. Youth Agency

8. Externalizing YR

9. Externalizing PR

10. Internalizing YR

11.Internalizing PR

12. MP Global

13. 1.111P Listen w/Full

Attn.

14. !'AP Emotiona

Alvare.

15. ! MP Self Regulation

16. !MPNonJudg Accept.

17. !łP Compassion

M

SD

$$
2
$$

4

$$
5
$$

$39 * \quad 22$

$\begin{array}{llll}24 & -.04 \quad 07 & 07\end{array}$

$\begin{array}{llll}.50 * * & .14 & .37 * & 28\end{array}$

$\begin{array}{llll}.14 & -29 & .17 & -01\end{array}$

$\begin{array}{llll}.30 & -.33 & .16 & .08\end{array}$

$\begin{array}{llll}.03 & 29 & -.02 & -.36\end{array}$

$25.44 * \quad .03 \quad 24$

$\begin{array}{llll}-.13 & .18 & -.06 & -23\end{array}$

$\begin{array}{llll}.05 & 33 & 03 & -03\end{array}$

$\begin{array}{llll}.09 & -.06 & 28 & 25\end{array}$

$\begin{array}{llll}-.02 & -.03 & .15 & 25\end{array}$

$23 \quad 05 \quad 20 \quad 31$

$\begin{array}{llll}20 & -.06 & .17\end{array}$

$.08 \quad .19$

$.03 \quad .01 \quad 27$

$\begin{array}{llll}.51 & 68 & 42,474 & .48\end{array}$

\begin{tabular}{|c|c|c|c|c|c|c|c|c|c|c|c|}
\hline .15 & $7 \mathbf{P}^{* * *}$ & & & & & & & & & & \\
\hline .07 & $-.53^{* *}$ & $-.43^{*}$ & & & & & & & & & \\
\hline-.07 & $-.59 * *$ & $-.48 * *$ & .22 & I & & & & & & & \\
\hline $\begin{array}{l}-.12 \\
-.00\end{array}$ & $\begin{array}{l}-.71^{* *} \\
-.60^{* *}\end{array}$ & $\begin{array}{l}-.51^{* *} \\
-67^{* *}\end{array}$ & $\begin{array}{l}.71^{* *} \\
.39 *\end{array}$ & $\begin{array}{c}20 \\
.71^{* *}\end{array}$ & $.55^{* *}$ & & & & & & \\
\hline 4 & .34 & .09 & -.33 & -.31 & -.23 & -24 & & & & & \\
\hline $.42 *$ & 23 & .02 & -29 & -.25 & -.26 & -.32 & SO•• & & & & \\
\hline $.57 *$ & .35 & .22 & -.30 & -.29 & -.26 & -35 & $.84 * *$ & $.69 * \bullet$ & & & \\
\hline .27 & .35 & .06 & $-.44 *$ & -.33 & -.22 & -.19 & $.74 * *$ & $11 \bullet$ & $.68 \bullet *$ & & \\
\hline 4 & $.37 *$ & .15 & -.14 & -.35 & -.16 & -28 & $.85 * *$ & $.64 * *$ &.$\& 1 \bullet \bullet$ & $.57 * *$ & \\
\hline .17 & 33 & .10 & -.30 & -.35 & -.21 & -29 & $92 *_{\bullet}$ & $6 \& \bullet \bullet$ &.$S O^{\bullet \bullet}$ & $.62 * *$ & $.88^{* *}$ \\
\hline 5.13 & 2.87 & 2.15 & 8.13 & 6.9 & 6.83 & 6.7 & 2.78 & 2.77 & 2.47 & 2.95 & 2.8 \\
\hline 1.38 & .75 & .49 & 8.19 & 6.34 & 7.57 & 7.86 & .81 & .93 & .73 & .76 & .71 \\
\hline
\end{tabular}

$\bullet=p<.05, \bullet=p<.01$ 
Combined and Unique Associations of Emotional Availability and Mindful Parenting with Adolescent Outcomes

Regression analyses were used to test the hypotheses that Emotional Availability (EA) and Mindful Parenting (MP) variables would show significant unique and combined relationships with adolescent outcome variables. Because the sample size of 30 and a potentially large number of independent variables (EA and $\mathrm{MP}$ ) greatly reduces power to detect significant effects, I chose to limit the number of variables entered into the regression equation. For each regression, correlations were used to determine the EA and MP variables with the strongest associations with the adolescent outcomes and those were used as predictors. When multiple variables had identical correlations to the outcome variable, both were used in separate analyses and the strongest of the two is presented in tables 4, 5, and 6. For each outcome variable, predictors were alternately entered in step 2 or step 3 to test for the additional variance accounted for by each independently. Step 1 in each regression included the control variables; step 2 included either selected EA or MP variables and indicated variable accounted for independently; and step 3 included EA or MP variables and indicated variable accounted for after accounting for the other.

Youth- and Parent-Reported Youth Internalizing Problems

As presented in table 4, EA youth responsiveness is a significant independent predictor of parent reported youth internalizing problems after controlling for the demographic variables (Rsquared $=.19$ ) and was also a unique predictor accounting for an additional $11 \%$ of the variance after emotional awareness was entered in the equation. In contrast, emotional awareness was a significant predictor independently, but did not account for additional variable after youth responsiveness was entered. Neither emotional awareness of self and child nor youth 
responsiveness are significant predictors of youth-reported internalizing problems. In this analysis, the intervention condition was the only significant predictor. MP listening with full attention was also used in analyses because it had an identical correlation as emotional awareness of self and child with youth-reported internalizing problems; however, its effects were weaker and therefore, were not presented in the table. 
Table 4

Hierarchical Regression Analyses of Observed Emotional Availability and Mindful Parenting Predicting Parent- and Youth-Reports of Youth Internalizing Problems

\begin{tabular}{|c|c|c|c|c|c|c|}
\hline & \multicolumn{3}{|c|}{ Parent-Reported Internalizing Problems } & \multicolumn{3}{|c|}{ Youth-Reported Internalizing Problems } \\
\hline Variable & $\Delta \mathrm{R}^{2}$ & $\begin{array}{l}\mathrm{B} \\
(\mathrm{SE} \mathrm{B})\end{array}$ & $\beta$ & $\Delta \mathrm{R}^{2}$ & $\begin{array}{l}\mathrm{B} \\
(\mathrm{SEB})\end{array}$ & $\beta$ \\
\hline $\begin{array}{l}\text { Step } 1 \\
\qquad \text { Sex }(1=\text { male, } 0=\text { female })\end{array}$ & .11 & $\begin{array}{l}-.54 \\
(2.98)\end{array}$ & -.04 & $.31^{* *}$ & $\begin{array}{l}-.03 \\
(.17)\end{array}$ & -.04 \\
\hline Age & & $\begin{array}{l}3.22 \\
(1.9)\end{array}$ & .28 & & $\begin{array}{l}.07 \\
(.11)\end{array}$ & .11 \\
\hline Education & & $\begin{array}{l}1.26 \\
(1.19)\end{array}$ & .22 & & $\begin{array}{l}-.03 \\
(.07)\end{array}$ & -.10 \\
\hline Condition & & & & & $\begin{array}{l}-.28 \\
(.10)\end{array}$ & $-.53^{* * *}$ \\
\hline Step 2 & & & & & & \\
\hline EA Youth Responsiveness & $\begin{array}{l}.19^{*} \\
\left(.11^{*}\right)\end{array}$ & $\begin{array}{l}-2.28 \\
(1.09)\end{array}$ & $-.38^{*}$ & $\begin{array}{l}.06 \\
(.03)\end{array}$ & $\begin{array}{l}-.07 \\
(.06)\end{array}$ & -.21 \\
\hline MP Emotional Awareness & $\begin{array}{l}.015^{*} \\
(.07)\end{array}$ & $\begin{array}{l}-3.31 \\
(2.02)\end{array}$ & -.31 & $\begin{array}{l}.04 \\
(.02)\end{array}$ & $\begin{array}{l}-.10 \\
(.13)\end{array}$ & -.17 \\
\hline Total $\mathrm{R}^{2}$ & \multicolumn{3}{|c|}{$.37^{*}$} & \multicolumn{3}{|c|}{$.39^{*}$} \\
\hline Adjusted $R^{2}$ & \multicolumn{3}{|c|}{$.24^{*}$} & \multicolumn{3}{|c|}{$.23^{*}$} \\
\hline
\end{tabular}

${ }^{\dagger} \mathrm{p}<.10,{ }^{*} \mathrm{p}<.05,{ }^{* *} \mathrm{p}<.01,{ }^{* * *} \mathrm{p}<.001$ Note: Regression equations were run alternating EA and MP variables steps 2 and 3 . Values for unstandardized and standardized coefficients are taken from the full regression equation (following step 3 ). 
Youth- and Parent-Reported Youth Externalizing Problems

Regression analyses, including EA and MP variables with the strongest correlations to the outcome variables are presented in table 5. EA nonhostility has an identical correlation as EA youth responsiveness with parent-reported youth externalizing problems, and both relate similarly to the outcome variable in a regression analysis as they are each a significant predictor together but nonsignificant independently. Nonhostility has a slightly stronger relationship to parent-reported youth externalizing problems and was used in the analysis including the MP and outcome variables. Additionally, MP nonjudgmental acceptance of self and child has an identical correlation as MP compassion for self and child with parent-reported youth externalizing problems and were both included separate regression analyses. However, nonjudgmental acceptance of self and child is a statistically significant predictor of the outcome variable and is thus presented in table 5 as opposed to the nonsignificant predictor, compassion for self and child.

Control variables included in step 1 account for a significant amount of variance for parent-reported youth externalizing problems, but a nonsignificant amount for youth-reported youth externalizing problems. Age is the only significant control variable that contributes to parent-reported youth externalizing problems among the control variables. EA adult nonhostility is a statistically significant predictor of parent-reported youth externalizing problems, after accounting for nonjudgmental acceptance of self and child. Furthermore, nonjudgmental acceptance of self and child is a significant predictor of this outcome, after accounting for adult nonhostility. Analyses indicate EA youth responsiveness is a nonsignificant predictor of youthreported externalizing problems, after accounting for MP parental self-regulation. Additionally, maternal self-regulation is a significant predictor of youth-reported externalizing problems 
before accounting for youth responsiveness, suggesting the two may relate similarly to this outcome variable. 
Table 5

Hierarchical Regression Analyses of Observed Emotional Availability and Mindful Parenting Predicting Parent-and Youth-Reported Youth Externalizing Problems

\begin{tabular}{|c|c|c|c|c|c|c|}
\hline \multirow[b]{2}{*}{ Variable } & \multicolumn{3}{|c|}{ Parent-Reported Extemalizing Problems } & \multicolumn{3}{|c|}{ Youth-Reported Externalizing Problems } \\
\hline & ilR $^{2}$ & $\begin{array}{l}\mathrm{B} \\
\text { (SE B) }\end{array}$ & & ilR $^{2}$ & $\begin{array}{l}\mathrm{B} \\
(\mathrm{SE} B)\end{array}$ & \\
\hline Step 1 & $.32^{*}$ & & & .08 & & \\
\hline Se'- $<(1=$ male, $0=$ female $)$ & & $\begin{array}{l}1.82 \\
(2.18)\end{array}$ & .15 & & $\begin{array}{l}40 \\
(3.34)\end{array}$ & -03 \\
\hline Age & & $\begin{array}{l}4.39 \\
(1.32)\end{array}$ & $.47^{* *}$ & & $\begin{array}{l}2.65 \\
(2.08)\end{array}$ & .22 \\
\hline Education & & $\begin{array}{l}.76 \\
(1.0)\end{array}$ & .17 & & $\begin{array}{l}1.22 \\
(127)\end{array}$ & .21 \\
\hline \multicolumn{7}{|l|}{$\begin{array}{l}\text { Step2 } \\
\text { (Step3) }\end{array}$} \\
\hline EA Adult NonHostility & $\begin{array}{l}.14 * \\
(.09 *)\end{array}$ & $\begin{array}{l}-1.74 \\
(.80)\end{array}$ & $-37 *$ & & & \\
\hline EA Youth Responsiveness & & & & $\begin{array}{l}.121 \\
(.02)\end{array}$ & $\begin{array}{l}-1.17 \\
(1.32)\end{array}$ & -.19 \\
\hline !VIP Nonjudgmental Acceptance & $\begin{array}{l}.13^{*} \\
\left(.08^{*}\right)\end{array}$ & $\begin{array}{l}-3.34 \\
(1.62)\end{array}$ & $-38 *$ & & & \\
\hline !VIP Self Regulation & & & & $\begin{array}{l}.20^{*} \\
\text { (.10ti }\end{array}$ & $\begin{array}{l}-4.05 \\
(2.22)\end{array}$ & $-38 t$ \\
\hline Total R' & & & & & & \\
\hline Adjusted R' & & & & & & \\
\hline
\end{tabular}




\section{Youth Life Satisfaction and Youth Agency}

EA mother clinical screener scores and MP nonjudgmental acceptance of self and child were selected for regression analyses with youth-reported life satisfaction. EA adult structuring and MP emotional awareness of self and child were selected for regression analyses with youthreported youth agency. Results, presented in table 6, indicate there are no statistically significant predictors of youth life satisfaction or youth agency among EA or MP variables. However, there are statistical trends at the .10 level of weak associations between mother clinical screener scores and MP nonjudgmental acceptance and life satisfaction. Additionally, among control variables, age is a significant predictor of youth-reported life satisfaction. 
Table 6

Hierarchical Regression Analyses of Observed Emotional Availability and Mindful Parenting Predicting Youth-Reported Youth Life Satisfaction and Agency

\begin{tabular}{|c|c|c|c|c|c|c|}
\hline \multirow[b]{2}{*}{ Variable } & \multicolumn{3}{|c|}{ Youth-Reported Life Satisfaction } & \multicolumn{3}{|c|}{ Youth-Reported Youth Agency } \\
\hline & $\Delta \mathrm{R}^{2}$ & $\begin{array}{l}\text { B } \\
\text { (SE B) }\end{array}$ & $\beta$ & $\Delta \mathrm{R}^{2}$ & $\begin{array}{l}\mathrm{B} \\
\text { (SE B) }\end{array}$ & $\beta$ \\
\hline Step 1 & $.21^{\dagger}$ & & & $.22^{\dagger}$ & & \\
\hline $\operatorname{Sex}(1=$ male, $0=$ female $)$ & & $\begin{array}{l}.15 \\
(.30)\end{array}$ & .10 & & $\begin{array}{l}.30 \\
(.20)\end{array}$ & .31 \\
\hline Age & & $\begin{array}{c}-.41 \\
(.19)\end{array}$ & $-.37^{*}$ & & $\begin{array}{l}-.24 \\
(.13)\end{array}$ & $-.33^{\dagger}$ \\
\hline Education & & $\begin{array}{l}.01 \\
(.14)\end{array}$ & .03 & & $\begin{array}{l}-.04 \\
(.08)\end{array}$ & -.10 \\
\hline Step 2 - EA Adult Structuring & -- & -- & -- & $\begin{array}{l}.03 \\
(.02)\end{array}$ & $\begin{array}{l}.08 \\
(.10)\end{array}$ & .17 \\
\hline Step 2 -EA Mother CS & $\begin{array}{l}.09^{\dagger} \\
(.05)\end{array}$ & $\begin{array}{l}.02 \\
(.01)\end{array}$ & .27 & -- & -- & -- \\
\hline $\begin{array}{l}\text { Step 2-MP Nonjudgmental } \\
\text { Acceptance }\end{array}$ & $\begin{array}{l}.08^{\dagger} \\
(.04)\end{array}$ & $\begin{array}{l}.29 \\
(.24)\end{array}$ & .27 & -- & -- & -- \\
\hline Step 2 - MP Emotional Awareness & -- & -- & -- & $\begin{array}{l}.03 \\
(.01)\end{array}$ & $\begin{array}{l}.08 \\
(.14)\end{array}$ & .13 \\
\hline Total $R^{2}$ & & & & & & \\
\hline Adjusted $R^{2}$ & & & & & & \\
\hline
\end{tabular}

${ }^{\dagger} p<.10, * p<.05, * * p<.01, * * * p<.001$ Note: Regression equations were run alternating EA and MP variables steps 2 and 3 . Values for unstandardized and standardized coefficients are taken from the full regression equation (following step 3 ). 


\section{DISCUSSION}

This study examined the association between Emotional Availability (EA) and Mindful Parenting (MP) in mother-adolescent relationships. Additionally, I examined the combined and unique associations that MP and EA have with measures of adolescent well-being including youth life satisfaction, youth agency, and youth internalizing and externalizing problems. These analyses allowed me to examine whether the constructs of EA and MP are associated with adolescent well-being outcomes in similar or unique ways. Two primary findings emerged from this study: global scales of EA and MP as well as many dimensions of EA and MP are significantly correlated, and specific EA and MP dimensions show unique and additive contributions of adolescent outcomes when accounting for the other.

Emotional Availability and Mindful Parenting

It was predicted that EA and MP would be significantly associated due to many conceptual overlaps between the two constructs. Results supported this hypothesis and indicated relationships between specific components of EA and MP, as well as global ratings of the constructs. That the global scores of the maternal EA and MP construct are strongly correlated indicates that high quality mother-adolescent relationships also tend to have higher levels of mindful parenting. This finding is interesting because it provides insight to how specific parenting behaviors, captured in the MP construct, are related to mother-child relationship quality, captured in the EA construct. Although there are conceptual similarities and a correlation between the two broad constructs, it is also important to consider which EA Scales are related to specific dimensions of MP, and which elements are unrelated or capture entirely unique aspects of mother-adolescent relationships. The strongest associations emerged between 
the MP scale of parental self-regulation, and several EA Scales including overall zones of emotional availability for both mother and youth, which indicates more secure emotional attachment. This suggests mothers who are better able to regulate their own emotions, as evidenced by low levels of defensiveness, infrequent negative affect, and appropriate responses through the coding of the MP scales (Duncan et al., 2009), are more likely to exhibit behaviors that contribute to emotional availability and attachment security. For example, a mother who can regulate her emotions (such as impatience, frustration, boredom) is also more available to show sensitivity to her adolescent as evidenced by a balanced affect, positive engagement and enjoyment of the youth without seeming distracted, and responding appropriately and respectfully to the youth's needs (Biringen, 2008).

Adult nonhostility also relates to maternal self-regulation, both conceptually and statistically. Adult nonhostility requires a mother to inhibit negativity in her face or voice; be well-regulated in that she does not 'lose her cool' in stressful circumstances; and avoid harsh styles of engagement such as hostile play themes, threats of separation, silence, or frightening behaviors (Biringen, 2008). Thus, self-regulation is incorporated in the way nonhostility is defined, and correlations indicate mothers who display nonhostility with their youth by the EA coding system also exhibit higher levels of self-regulation in the MP coding system. Additionally, youth responsiveness and youth involvement are correlated with mothers' selfregulation. This suggests adolescents are more eager to engage with their mother in a positive, enthusiastic, and appropriate manner, and initiate elaborated engagement with their mother when the mother is well-regulated. In an interaction, this may include a youth who is emotionally responsive to the mother by maintaining a balanced and positive affect while looking, talking, and responding to mother's initiatives, without any indications of anxiety or dysregulation, and 
introducing opportunities to involve the mother through eye contact, body positioning, and verbal prompts (Biringen, 2008). This emotional responsiveness and involvement are more likely to exist in a relationship in which the mother is able to regulate her own emotions (such as negative affect and defensiveness) and respond with appropriate timing and intensity, which is also consistent with previous findings that mindful parents have a greater ability to regulate their own emotions and provide consistent parenting (Parent et al., 2015). This is a particularly interesting finding because the MP rating is designed to focus on the mother's behavior and the EA Scales of youth responsiveness and youth involvement are focused on the youth. Thus, there are independent targets of coding for these dimensions, yet the associated ratings of the mother's and youth's behavior teach us something unique about the interaction and relationship. Additional features of EA that are correlated with self-regulation include adult structuring, or providing appropriate guidance and support for the interaction, and youth involvement in which the youth appropriately elaborates and seeks to involve adult in interaction (Biringen, 2008). In an interaction, this may present as a mother who asks the youth unprompted questions to further the conversation and elicit additional response from the youth (structuring).

In addition to self-regulation, several specific EA Scales are related to all MP dimensions including overall emotional availability (emotional attachment) of the mother, adult sensitivity, adult structuring, and adult nonhostility. This suggests mothers who exhibit high emotional availability and provide opportunities for a secure attachment, are sensitive and appropriately responsive to their adolescents, provide appropriate and sufficient guidance and support to their youth, and exhibit low hostility in affect and behavior are more likely to exhibit mindful parenting behaviors (Biringen, 2008). Based on correlations, there are some exceptions to this pattern that should be noted. Adult structuring, which involves providing guidance and 
establishing appropriate boundaries, is not related to compassion for self and child, which involves a lack of contempt and displays of affection, empathy, and concern for the youth. This finding is surprising considering an ideal level of structuring, as coded by the EA Scales, requires guidance to be provided in such a way that is not overpowering and that is successful and appropriate in the dyadic interaction with the youth. Thus, it seems that appropriate structuring would require an empathetic consideration for the youth's experience as well as an affectionate manner of guidance that would elicit a successful response. Another exception is adult nonhostility not being related to listening with full attention. This finding indicates mothers who exhibit low hostility within interactions with their youth may not be more likely to listen with full attention, through focused attention and verbal reciprocity (or meaningful participation in response to youth). This is interesting when considering the link between nonhostility and self-regulation and it might be expected that mothers who are well-regulated and refrain from reactive or disrespectful behaviors, would also exhibit more attentiveness when listening or interacting with their youth. However, it appears that behaviors required for listening with full attention (not being distracted and aligning speech with the youth's meaning) are uniquely distinct from the lack of hostility and presence of self-regulation. Otherwise stated, parents may be focused, attentive, and well-regulated, but can still be relatively hostile, such as with subtle statements of hostility that require careful listening.

Interestingly, all EA Scales except adult nonintrusiveness are related to at least one dimension of MP. This could indicate that nonintrusiveness is a unique component of EA and captures some aspect of the mother-adolescent relationship that MP dimensions do not. This is somewhat unexpected because the concept of nonintrusiveness (being available to the adolescent in the relationship without over-mentoring, over structuring, or providing too much guidance) is 
integrated within some MP dimensions. For example, the element of attentive listening in coding for listening with full attention requires a mother's focus on the youth and alignment of speech to match the youth's meaning (Duncan et al., 2009), which seems to capture elements of nonintrusiveness. Nonjudgmental acceptance also requires the ability to accept and validate youth's expressions (Duncan et al., 2009), which is consistent with nonintrusive properties of following the youth's lead in an interaction. Nonintrusiveness might be observed in an interaction with a mother allowing the youth to read their own conversation question card and respond without interruption (verbal or nonverbal- such as cutting the youth off, arguing, or physically taking the card away), and will not use conversation as an opportunity to lecture or over-teach the youth. It may be that MP scales incorporate elements of nonintrusiveness, while not explicitly assessing for intrusive behaviors (physical intrusions, verbal interruptions, preventing opportunities for the youth to exhibit autonomy), as the EA Scale does.

One important factor to consider in the interpretation of these findings is that the EA measures include adult and youth behaviors while MP incorporates only maternal behaviors. Although both constructs take the dyadic interaction with a youth into account, it would be expected that elements of youth specific measures would be unique to EA. Results show numerous relations between youth responsiveness and MP dimensions, including global scores, but only one relation for youth involvement and overall youth emotional availability (attachment) with MP maternal self-regulation. Specifically, youth appear to show more responsiveness with mothers who listen with full attention, have emotional awareness of themselves and the youth, self-regulate, and have nonjudgmental acceptance of themselves and the youth. This is especially interesting when considering youth clinical screener scores are strongly statistically related to and conceptually informed by youth responsiveness, yet relate 
more similarly as youth involvement to these MP dimensions. One way of interpreting this is that youth involvement and youth emotional availability are relatively unique to EA, and youth responsiveness may capture similar elements of the mother-adolescent relationship as MP dimensions.

From a correlational perspective, it appears that EA has several components that are not related to MP and capture unique elements of the relationship, many of which exist in youth scales. Additionally, there are no MP dimensions that are not related to some aspect of EA, suggesting there are many overlaps between these constructs. Correlations between these constructs are depicted in figure 3. One interpretation of these results is to provide support for Harnett and Dawe's (2012) integrated model of family functioning, which suggests mindful parenting is a means for enabling parents to be emotionally available in their relationships with their children, as it enhances their self-regulatory capacities and allows for consistent parenting. Because the largest number of correlations are seen between EA Scales and MP self-regulation, results from this study would be consistent with the integrated model theory. However, although there are many similarities between the constructs of EA and MP, there is reason to believe each construct provides unique contributions to understanding mother-adolescent relationships, which is supported further through relationships with adolescent outcomes. 


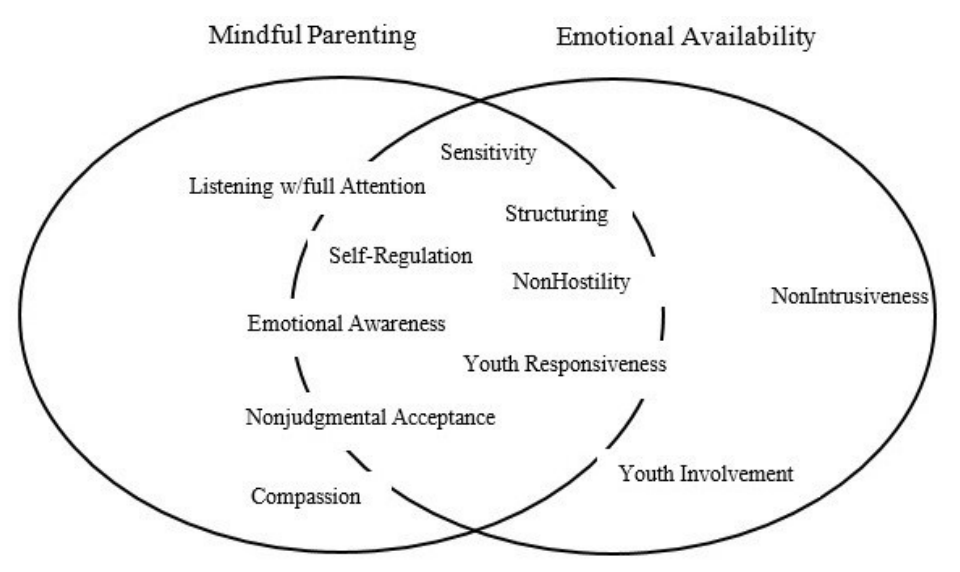

Figure 3. Correlations between EA and MP dimensions.

Emotional Availability and Mindful Parenting with Adolescent Outcomes

The second hypothesis in this study predicted Emotional Availability (EA) and Mindful Parenting (MP) scales would show significant combined and unique associations with adolescent outcomes. Results indicate EA and MP have unique relationships with adolescent outcomes in both zero-order correlations and regression analyses.

Emotional Availability with Adolescent Outcomes

The strong associations between EA Scales and life satisfaction suggests that youth with more emotionally available mother-adolescent relationships are more likely to report high life satisfaction. More specifically, emotionally available relationships that relate to life satisfaction involve youth who are appropriately responsive and involving, and mothers who are appropriately sensitive and structuring, contributing to more overall emotional availability and emotional attachment. This finding is consistent with existing literature that indicates highquality parent-adolescent relationships relate to fewer internalizing and externalizing problems as well as intimate relationship quality in young adulthood (Johnson \& Galambos, 2014). Additionally, mothers are more likely to report youth externalizing problems when mothers exhibit higher levels of hostility and when youth are less responsive. Parents are also more 
likely to report youth internalizing problems when youth are less responsive. This finding is consistent with previous studies indicating high-quality mother-adolescent relationships serves as a protective factor for adolescent internalizing and externalizing problems (McWey et al., 2015). Additionally, it supports that patterns found in middle childhood, such as effective discipline predicting improvements in internalizing and externalizing problems, continue into adolescence (McClain et al., 2010). Finally, parenting involving harsh discipline is a strong predictor of externalizing problems and aggression in adolescents (Liu, Wei, Xing, \& Wang, 2012). Mindful Parenting with Adolescent Outcomes

MP dimensions are significantly correlated to adolescent outcomes including life satisfaction and youth reported externalizing problems. Youth are more likely to report high life satisfaction when mothers exhibit a nonjudgmental acceptance of themselves and their child. Thus, adolescents are more likely to report life satisfaction with mothers who exhibit interest toward their thoughts, feelings, and behaviors without judgement, and who validate such features of the youth. This is interesting considering the correlation between nonjudgmental acceptance of self and child and mother-adolescent relationship quality (as measured by EA Scales), which is also strongly related life satisfaction. Additionally, youth are more likely to report externalizing problems when mothers have lower levels of self-regulation. Mothers with poor self-regulation may exhibit defensiveness, negative affect, and strong negatively reactive responses to the youth. Thus, it is reasonable to consider how adolescent children of such mothers would manage negative emotions poorly in the form of externalizing behaviors (aggression, delinquency, etc.). This finding provides support of previous research indicating a connection between parenting behaviors and youth externalizing problems (Forehand et al., 2013). 
Unique and Combined Relationships with Adolescent Outcomes

Although there were many statistically significant associations between EA and MP constructs, and both showed significant associations with youth outcomes, the correlations were generally moderate in magnitude, suggesting these constructs are also independent in some respects. I tested that idea further in regression analyses in which unique relationships were determined between components from each construct and specific outcomes, after accounting for the other. My hypothesis was partially supported as parent reports of their youth's internalizing problems (such as anxiety, depression, etc.) is predicted by low youth responsiveness (that is when their adolescent is less enthusiastic, bland, or disengaged), after accounting for influences of mothers' low emotional awareness of themselves and their child. Thus, (low) youth responsiveness is a unique EA contributor to indicators of youth internalizing problems, distinct from MP. Youth responsiveness is unique to EA because of the different focus on the youth's behaviors as opposed to the mother's behaviors, however its effect on parent reports of youth internalizing problems may indicate the effect of youth behavior on the mother-child relationship through specific interactions. For example, responsive youth behaviors may be one way in which mothers and their children have bidirectional influences on one another, which impacts the overall quality of the relationship and in turn, adolescent outcomes.

Further support for my hypothesis is seen in parents reporting more youth externalizing problems (aggression, delinquency, etc.) when parents exhibit higher levels of hostility (low nonhostility), after accounting for effects from parents having low nonjudgmental acceptance of themselves and their child. Thus, (low) nonhostility is a unique EA contributor to indicators of youth externalizing problems, distinct from MP. There may be behaviors of explicit hostility (captured in nonhostility) that may not be encompassed in MP dimensions, and such behaviors 
predict adolescent outcomes. Additionally, parents report more youth externalizing problems when mothers exhibit less nonjudgmental acceptance for themselves and their child, after accounting for higher levels of parental hostility (low nonhostility). Thus, (low) nonjudgmental acceptance of self and child is an MP dimension independently linked with indicators of youth externalizing problems, distinct from EA. This dimension may capture beneficial elements of positive mother-child relationships that is not captured in EA Scales, and these elements predict adolescent outcomes. Moreover, EA Scales uniquely contribute to parent-reported youth internalizing and externalizing problems, and MP uniquely contributes to parent-reported youth externalizing problems.

Interestingly, despite numerous correlations with EA Scales and an MP dimension, results did not determine unique predictive relationships with life satisfaction. Mothers' overall emotional availability and nonjudgmental acceptance are not unique predictors of youth life satisfaction, after accounting for the other. This may be due to these components being strongly correlated and overlapping in their contributions to youth life satisfaction. Because there are so many correlations between dimensions of EA and MP, it may be important to consider how this could have impacted the unique predictive abilities of each component for adolescent outcomes. It is possible that the dimensions included in analyses were correlated in ways that similarly contribute to the adolescent outcome variables, thus confounding each other. Perhaps if alternative correlated scales and dimensions were paired in analyses, there would be more to learn about how each construct relates to adolescent outcomes. 


\section{Limitations and Future Directions}

\section{Limitations}

The current study was an initial empirical examination of the associations between Emotional Availability (EA) and Mindful Parenting (MP), as well as their contributions to adolescent outcomes. One of the most significant limitations was a small sample size, which resulted in low power and limited ability to detect and examine relationships that exist. This also contributed to greater risk for type II errors and being unable to detect small effects that may exist. The small sample size also increased influence of a single case on the analysis results, creating risk for outliers to unduly impact correlations. Additionally, the observational task used in this study was designed for the Iowa Family Rating Scales and not specifically for assessing either MP or EA. Therefore, the context was limited as the purpose was to examine general patterns of interactions.

\section{Future Directions}

The current study provided a preliminary investigation to review findings that might suggest directions for future studies in this area. There are many areas in need of further exploration on this subject. To my knowledge, this study is the first of its kind to empirically examine the relationship between these two constructs. Harnett and Dawe (2012) suggested a theoretical model of integration that is supported with findings in this report, however further exploration is needed to examine this model more specifically. Future studies will need to examine this association further to determine which components of EA and MP are similar or unique in contributing to mother-adolescent relationship quality and adolescent well-being. For example, because there were numerous relationships suggesting overlap of MP elements with EA Scales, and EA Scales having more unique features, future research could examine a potential mediating 
relationship of MP between EA and mother-adolescent relationship quality as well as adolescent outcomes. Furthermore, incorporating these kinds of measures into an intervention to enhance MP or EA, could help to illustrate the correlations between these constructs more definitively. There is also sparse empirical work exploring EA in adolescence, despite a vast amount of literature emphasizing the importance of mother-adolescent relationships and developmental outcomes. Additional exploration of EA within this demographic is important to consider how quality of mother-adolescent relationships contributes to adolescent well-being. It will also be important to expand the demographic to include fathers and variations in two-parent homes when examining these relationships. Interventions to increase EA in mother-adolescent relationships may be useful in furthering understanding of its relationship to adolescent well-being. 


\section{REFERENCES}

Achenbach, T. M., \& Rescorla, L. A. (2001). Manual for the ASEBA school-age forms \& profiles. Burlington, VT: University of Vermont, Research Center for Children, Youth, \& Families.

Allen, J. P., Porter, M., McFarland, C., McElhaney, K. B., \& Marsh, P. (2007). The relation of attachment security to adolescents' paternal and peer relationships, depression, and externalizing behavior. Child Development, 78, 1222-1239. doi: 10.1111/j.14678624.2007.01062.x

Altenhofen, S., Sutherland, K., Biringen, Z. (2010). Families experiencing divorce: Age at onset of overnight stays, conflict, and emotional availability as predictors of child attachment. Journal of Divorce \& Remarriage, 51(3), 141-156

Baer, R. A., Smith, G. T., Hopkins, J., Krietemeyer, J., \& Toney, L. (2006). Using self-report assessment methods to explore facets of mindfulness. Assessment, 13, 27-45. doi: 10.1177/1073191105283504.

Barnes, S., Brown, K. W., Krusemark, E., Campbell, W. K., \& Rogge, R. D. (2007). The role of mindfulness in romantic relationship satisfaction and responses to relationship stress. Journal of Marital and Family Therapy, 33(4), 482-500. doi:10.1111/ j.17520606.2007.00033.x.

Biringen, Z. (2008) The Emotional Availability (EA) Scales Manual. $4^{\text {th }}$ edition, Middle Childhood/ Youth Version. Published by emotionalavailability.com, PO Box, 3625, Boulder, Colorado 80307 
Biringen, Z., Altenhofen, S., Aberle, J., Baker, M., Brosal, A., Bennett, S., \& ... Swaim, R. (2012). Emotional availability, attachment, and intervention in center-based child care for infants and toddlers. Development and Psychopathology, 24(1), 23-34. doi:10.1017/S0954579411000630

Biringen, Z., Derscheid, D., Vliegen, N., Closson, L., \& Easterbrooks, M. A. (2014). Emotional availability(EA): Theoretical background, empirical research using theEA Scales, and clinical applications. Developmental Review, 34, 114-167. doi: 10.1016/j.dr.2014.01.002

Biringen, Z., \& Easterbrooks, M. A. (2012). Emotional availability: Concept, research, and window on developmental psychopathology. Development and Psychopathology, 24, 1-8. doi:10.1017/S0954579411000617

Bögels, S., Hoogstad, B., van Dun, L., de Schutter, S., \& Restifo, K. (2008). Mindfulness training for adolescents with externalizing disorders and their parents. Behavioural and Cognitive Psychotherapy, 36(2), 193-209. doi:10.1017/S1352465808004190

Bornstein, M. H., Gini, M., Putnick, D. L., Haynes, O. M., Painter, K. M., \& Suwalsky, J. D. (2006). Short-term reliability and continuity of Emotional Availability in mother-child dyads across contexts of observation. Infancy, 10(1), 1-16. doi:10.1207/s15327078IN1001_1

Bradley, S. (2013). Adolescent agency: A conceptual model, measurement, and construct validity. Unpublished doctoral dissertation, The Pennsylvania State University. State College, PA.

Brown, K. W., \& Ryan, R. M. (2003). The benefits of being present: Mindfulness and its role in psychological well-being. Journal of Personality and Social Psychology, 84(4), 822-848. 
Brown, K. W., Ryan, R. M., \& Creswell, J. D. (2007). Mindfulness: Theoretical foundations and evidence for its salutary effects. Psychological Inquiry, 18(4), 211-237. doi:10.1080/10478400701598298 doi:10.1037/0022-3514.84.4.822

Bryan, M. G., Coatsworth, J. D., \& Greenberg, M. T. (2016). The Mindful Parenting Observational Scales (MPOS): Theoretical background and preliminary evidence for inter-rater reliability and incremental validity. Unpublished manuscript, The Pennsylvania State University; The Colorado State University.

Carmody, J., \& Baer, R. A. (2008). Relationships between mindfulness practice and levels of mindfulness, medical and psychological symptoms and well-being in a mindfulnessbased stress reduction program. Journal of Behavioral Medicine, 31, 23-33. doi:10.1007/s10865-007-9130-7.

Carson, J. W., Carson, K. M., Gil, K. M., \& Baucom, D. H. (2004). Mindfulness-based relationship enhancement. Behavior Therapy, 35, 471-494. doi:10.1016/S00057894(04)80028-5.

Coatsworth, J. D., Duncan, L. G., Greenberg, M. T., \& Nix, R. L. (2010). Changing parent's mindfulness, child management skills and relationship quality with their youth: Results from a randomized pilot intervention trial. Journal of Child and Family Studies, 19, 203217. doi: 10.1007/s10826-009-9304-8

Coatsworth, J. D., Duncan, L. G., Nix, R. L., Greenberg, M. T., Gayles, J. G., Bamberger, K. T., \& ... Demi, M. A. (2015). Integrating mindfulness with parent training: Effects of the mindfulness-enhanced strengthening families program. Developmental Psychology, 51(1), 26-35. doi:10.1037/a0038212 
Cohen, J. S., \& Semple, R. J. (2010). Mindful parenting: A call for research. Journal of Child and Family Studies, 19(2), 145-151. doi:10.1007/s10826-009-9285-7

De Falco, S., Emer, A., Martini, L., Rigo, P., Pruner, S., \& Venuti, P. (2014). Predictors of mother-child interaction quality and child attachment security in at-risk families. Frontiers In Psychology, 5, http://dx.doi.org/10.3389/fpsyg.2014.00898

Duncan, L. G. (2007). Assessment of mindful parenting among parents of early adolescents: Development and validation of the Interpersonal Mindfulness in Parenting scale. Unpublished dissertation.

Duncan, L.G., Coatsworth, J.D., Gayles, J.G., Geier, M.H., \& Greenberg, M.T. (2015). Can mindful parenting be observed? Relations between observational ratings of mother-youth interactions and mothers' self-report of mindful parenting. Journal of Family Psychology, 29(2), 276-282. doi 10.1037/a0038857

Duncan, L. G., Coatsworth, J. D., \& Greenberg, M. T. (2009). A model of mindful parenting: Implications for parent-child relationships and prevention research. Clinical Child and Family Psychology Review, 12, 255-270. doi:10.1007/s10567-009-0046-3

Easterbrooks, M. A., Biesecker, G., \& Lyons-Ruth, K. (2000). Infancy predictors of emotional availability in middle childhood: The roles of attachment security and maternal depressive symptomatology. Attachment \& Human Development, 2, 170-187. doi:10.1080/14616730050085545

Easterbrooks, M. A., \& Biringen, Z. (2000). Guest editors' introduction to the special issue: Mapping the terrain of emotional availability and attachment. Attachment \& Human Development, 2, 123-129. doi:10.1080/14616730050085518 
Easterbrooks, M. A., \& Biringen, Z. (2009). Introduction to the special issue: Emotional availability across contexts. Parenting: Science And Practice, 9(3-4), 179-182. doi:10.1080/15295190902844266

Easterbrooks, M. A., Bureau, J., \& Lyons-Ruth, K. (2012). Developmental correlates and predictors of emotional availability in mother-child interaction: A longitudinal study from infancy to middle childhood. Development and Psychopathology, 24(1), 65-78. doi:10.1017/S0954579411000666

Forehand, R., Jones, D. J., \& Parent, J. (2013). Behavioral parenting interventions for child disruptive behaviors and anxiety: What's different and what's the same. Clinical Psychology Review, 33(1), 133-145. doi:10.1016/j.cpr.2012.10.010

Geier, M. H., Coatsworth, J. D., Turksma, C., \& Greenberg, M.T. (2012). The Mindful Parenting Rating Scales Coding Manual. Unpublished manuscript. The Strengthening Families in Pennsylvania Project, Department of Health and Human Development, The Pennsylvania State University, State College, Pennsylvania.

Harnett, P. H., Dawe, S. (2012). Review: The contribution of mindfulness-based therapies for children and families and proposed conceptual integration. Child and Adolescent Mental Health, 17, 195-208. doi:10.1111/j.1475-3588.2011.00643.x

Howes, C., \& Hong, S. S. (2008). Early emotional availability: Predictive of pre-kindergarten relationships among Mexican-heritage children? Journal of Early Childhood and Infant Psychology, 4, 44-25.

Huebner, E. S. (1991). Initial development of the students' life satisfaction scale. School Psychology International, 12, 231-240 
Huebner, E. S., Suldo, S. M., \& Valois, R. F. (2003). Psychometric properties of two brief measures of Children’s Life Satisfaction: The Students' Life Satisfaction Scale (SLSS) and the brief multidimensional Students' Life Satisfaction Scale (BMSLSS). Paper presented at the Indicators of Positive Development Conference, University of South Carolina.

Johnson, M. D., \& Galambos, N. L. (2014). Paths to intimate relationship quality from parentadolescent relations and mental health. Journal of Marriage and Family, 76, 145-160.

Kogan, N., \& Carter, A. S. (1996). Mother-infant reengagement following the still-face: The role of maternal emotional availability in infant affect regulation. Infant Behavior \& Development, 19, 359-370. doi:10.1016/S0163-6383(96)90034Xdoi:10.1111/jomf.12074

Lippold, M. A., Duncan, L. G., Coatsworth, J. D., Nix, R. L., \& Greenberg, M. T. (2015). Understanding how mindful parenting may be linked to mother-adolescent communication. Journal of Youth and Adolescence, 44, 1663-1673. doi:10.1007/s10964015-0325-x

Liu, B., Wei, Z., Xing, X., \& Wang, M. (2012). Relations between paternal and maternal harsh disciplines and junior middle school students' externalizing problem behaviors. Chinese Journal Of Clinical Psychology, 20(6), 842-845.

Margolin, G., Oliver, P. H., Gordis, E. B., Garcia O'Hearn, H., Medina, A. M., Chosh, C. M., \& Morland, L. (1998). The nuts and bolts of behavioral observation of marital and family interaction. Clinical Child and Family Psychology, 1(4), 195-213

McClain, D. B., Wolchik, S. A., Winslow, E., Tein, J.-Y., Sandler, I. N., \& Millsap, R. E. (2010). Developmental cascade effects of the New Beginnings Program on adolescent adaptation 
outcomes. Development and Psychopathology, 22, 771-784.

doi:10.1017/S0954579410000453

McWey, L. M., Claridge, A. M., Wojciak, A. S., \& Lettenberger-Klein, C. G. (2015). Parentadolescent relationship quality as an intervening variable on adolescent outcomes among families at risk: Dyadic analyses. Family Relations: An Interdisciplinary Journal of Applied Family Studies, 64, 249-262. doi: 10.1111/fare.12111

Melby, J. N., Conger, R. D., Book, R. A., Rueter, M., Lucy, L., Repinski, D., Ahrens, K., Black, D., Brown, D., Huck, S., Mutchler, L., Rogers, S., Ross, J., \& Stavros, T. (1989). The Iowa Family Interaction Coding Manual. Unpublished manuscript, Iowa Youth and Families Project, Department of Sociology, Iowa State University, Ames, Iowa.

Molgaard, V. K., Spoth, R. L., \& Redmond, C. (2000). Competency Training: The Strengthening Families Program, for Parents and Youth 10-14: US Department of Justice, Office of Justice Programs, Office of Juvenile Justice and Delinquency Prevention Washington, DC.

Parent, J., McKee, L. G., Rough, J., \& Forehand, R. (2015). The association of parent mindfulness with parenting and youth psychopathology across three developmental stages. Journal of Abnormal Child Psychology. Advance online publication. doi:10.1007/s10802-015-9978-x

Reidler, E. B., \& Swenson, L. P. (2012). Discrepancies between youth and mothers' perceptions of their mother-child relationship quality and self-disclosure: Implications for youth- and mother-reported youth adjustment. Journal of Youth and Adolescence, 41(9), 1151-1167. doi:10.1007/s10964-012-9773-8 
Saunders, H., Kraus, A., Barone, L., \& Biringen, Z. (2015). Emotional availability: Theory, research, and intervention. Frontiers in Psychology, 6.

Zimmerman, L., \& McDonald, L. (1995). Emotional availability in infants' relationships with multiple caregivers. American Journal of Orthopsychiatry, 65, 147-152. doi:10.1037/h0079586

Ziv, Y., Aviezer, O., Gini, M., Sagi, A., \& Koren-Karie, N. (2000). Emotional availability in the mother-infant dyad as related to the quality of infant-mother attachment relationship. Attachment \& Human Development, 2, 149-169. doi:10.1080/14616730050085536 